CHAPTER 11

\title{
A HISTORY OF THE STUDY OF ECOLOGICAL NETWORKS
}

\section{Louis-Félix Bersier}

Unit of Ecology and Evolution, Fribourg University, ch. du Musée 10, CH-1700 Fribourg, Switzerland

\section{louis-felix.bersier@unifr.ch}

\section{Introduction}

Ecology is the science of how organisms interact with each other and with their environment. Given this definition, first proposed by Haeckel ${ }^{\mathrm{a}}$ (1866), a non-ecologist may suppose that the study of networks of interactions between species in ecosystems is a mature and wellestablished domain of ecology (1). It is not. A likely reason is the difficulty of documenting interactions: it is easy to observe organisms, but the examination of interactions of any kind between species is much more elusive. For this reason, the vast majority of studies in ecology and evolution deal with few interacting species. Fortunately, the study of ecological networks is currently enjoying a burst of interest and is promised a bright future - a paramount incentive for strong development of network analysis is the urgent need of an understanding of how ecosystems will react to global changes.

\footnotetext{
${ }^{a}$ The original definition is: "By ecology we mean the body of knowledge concerning the economy of nature - the investigation of the total relations of the animal both to its inorganic and its organic environment; including, above all, its amical and inimical relations with those animals and plants with which it comes directly or indirectly into contact - in a word, ecology is the study of all those complex interrelations referred to by Darwin as the conditions of the struggle for existence."(source: http:/www.unijena.de/-page-364-lang-en.html)
} 
In this chapter, I will review the major steps in the development of the study of ecological networks. I will discuss some hypotheses on the underlying processes behind observed patterns in network structure. Before going into the history and state-of-the-art of this research theme, it is first necessary to go through some definitions. Intraspecific interactions - interactions between members of the same species - are of course essential for survival and reproduction. They are very rich and give rise to complex hierarchical patterns of structured interactions. Intraspecific interactions will not be tackled in this chapter - with the exception of cannibalistic interactions - and I will concentrate only on interspecific interactions. Also, I will not concentrate on just one pair of interacting species, but on communities. A first difficulty lies in the definition of this term $(2,3)$. Typically, the term community defines the set of all species living in a given location (4). If the physical conditions in this location are more or less homogeneous, it forms a biotope and the species living in it a biocoenosis. Different biotopes of the same kind can be interspersed geographically and linked by migration of the constituent species; they are structured in so-called metacommunities (5). The term community is sometimes used to describe a subset of a whole community. This is unfortunate since precise words exist, but which definition is pertinent is most often easily deduced by the context. The smallest subset is a guild, a group of species using similar resources in a similar way (6). A group of taxonomically related species is a taxocene. This term is not widely used in ecological literature despite the fact that most studies and theories on biodiversity are best suited to such subsets (e.g. 7-9). When concentrating on feeding interactions between species, one can define a food-web, i.e. a group of species linked by such interactions, thus describing the paths by which biomass flows through the community.

A customarily used subset of food-web is the notion of trophic level, which typically describes a subset of a community with similar feeding habits, e.g. herbivores (see ref. 10 for other definitions). Finally, it is worth mentioning the concept of ecosystem, which not only considers the interactions between species in a community, but also the interactions between species and their physical environment. In the following, we 
will tackle mostly whole communities or subsets of them described by the type of interactions linking the species.

Classically, ecological interactions between species are classified according to their reciprocal effects (11). In this context, the effect of one species on another can be measured in terms of the consequences for growth rate, population size, or relative fitness. Relative fitness is the ratio of the growth rate of the species of interest in the presence of the interacting species to that in its absence. Figure 1 illustrates the possible outcomes for a pair of species. Typically, ecologists have tackled only one type of interaction at a time. Very few studies merge different interactions at the community level - for example predation and mutualism in Melián (2005) (12).

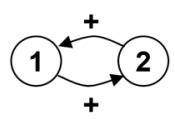

Mutualism

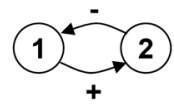

Predation

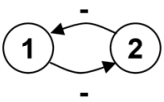

Competition

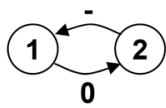

Amensalism

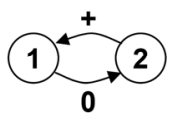

Commensalism

Figure 1. Types of biological interactions between two species. A zero indicates an absence of measurable effect.

When considering a group of species linked by one type of interaction, a useful representation of the topology of such an ecological network is a graph whose nodes (or vertices) are the members of the group, and whose links (or edges) are the interactions between them. Such a graph is undirected for mutualistic and competitive interactions, and directed for predation, amensalism, and commensalism. In the latter, edges have a direction and are sometimes called arcs. The same information can be captured in an adjacency matrix. This is a square binary matrix whose rows and columns are labelled by the members of the group ordered in a similar way. A zero in the matrix indicates an absence of interaction and a one an interaction between species in the corresponding row and column. Adjacency matrices are symmetric for undirected graphs but not for directed ones. For such non-symmetric matrices, it is necessary to indicate the status of the species. For trophic interactions, consumers are typically listed columnwise, and prey 
rowwise, forming a food-web matrix $A=\left[a_{i j}\right]$, with $a_{i j}=1$ if species $j$ consumes species $i$, and 0 otherwise.

There is little doubt that the interest and recognition of the importance of ecological networks was bolstered by Darwin (1859) (13) himself, when he described natural communities as an entangled bank:

"It is interesting to contemplate an entangled bank, clothed with many plants of many kinds, with birds singing on the bushes, with various insects flitting about, and with worms crawling through the damp earth, and to reflect that these elaborately constructed forms, so different from each other, and dependent on each other in so complex a manner, have all been produced by laws acting around us."

A description of these underlying laws is made more explicit when Darwin described the succession of forests:

"When we look at the plants and bushes clothing an entangled bank, we are tempted to attribute their proportional numbers and kinds to what we call chance. But how false a view is this! Every one has heard that when an American forest is cut down, a very different vegetation springs up; but it has been observed that the trees now growing on the ancient Indian mounds, in the Southern United States, display the same beautiful diversity and proportion of kinds as in the surrounding virgin forests. What a struggle between the several kinds of trees must here have gone on during long centuries, each annually scattering its seeds by the thousand; what war between insect and insect - between insects, snails, and other animals with birds and beasts of prey - all striving to increase, and all feeding on each other or on the trees or their seeds and seedlings, or on the other plants which first clothed the ground and thus checked the growth of the trees! Throw up a handful of feathers, and all must fall to the ground according to definite laws; but how simple is this problem compared to the action and reaction of the innumerable plants and animals which have determined, in the course of centuries, the proportional numbers and kinds of trees now growing on the old Indian ruins !"

Competitive and trophic interactions lie clearly at the heart of Darwin's concept of the entangled bank. But together with this admirable description comes the warning of the complexity of the task! And the discovery of underlying processes is not only a daunting undertaking, the 
simple description of the interactions between the members of a community is already a difficult exercise. Moreover, competition is observationally more elusive than predation, and it is the probable reason why ecologists have been historically more interested by ecological networks of trophic interactions - food-webs. We will now pass through some historically important cornerstones in the study of ecological networks. It is not in the scope of this chapter to describe comprehensively the history of the study of ecological networks. Interested readers can refer to authoritative works by Hagen (1992) (14), Golley (1993) (15), or by Kingsland (1995) (16) for history of dynamical models. My aim here is to review the principal contributions until the nineteen-seventies, and to pay more attention to the major routes of developments of this discipline since this period. As it will be apparent, the main body of research on the network of interactions between species in a community tackled the links between consumers and their prey. Network representations incorporating other kinds of interactions are much more recent.

\section{The pioneers}

The first attempt to represent the trophic interactions in a community as a network was made by the Italian scientist Lorenzo Camerano (1880) (17). Earlier verbal descriptions of food-webs existed (e.g. ref. 18), but Camerano was apparently the first to link species in a diagrammatic manner (19). It must be pointed out that nodes in Camerano's food-web are actually functional groups (e.g. amphibians, carnivorous fish) rather than true species (Fig. 2). The motivation behind this study was to provide a theoretical background to a practical problem: which animals are useful and which are harmful to crops, one of the most debated issues at that time. Camerano's contribution is extremely interesting for several reasons. First, it shows that the idea that communities are at equilibrium was prevalent at that time. Being at equilibrium means that the densities of the plants and animals do not vary "significantly" above or below what is usually observed. Camerano had a deep feeling that this equilibrium was achieved through fine-tuned interactions between species. The idea that communities are dynamic through species mutual 


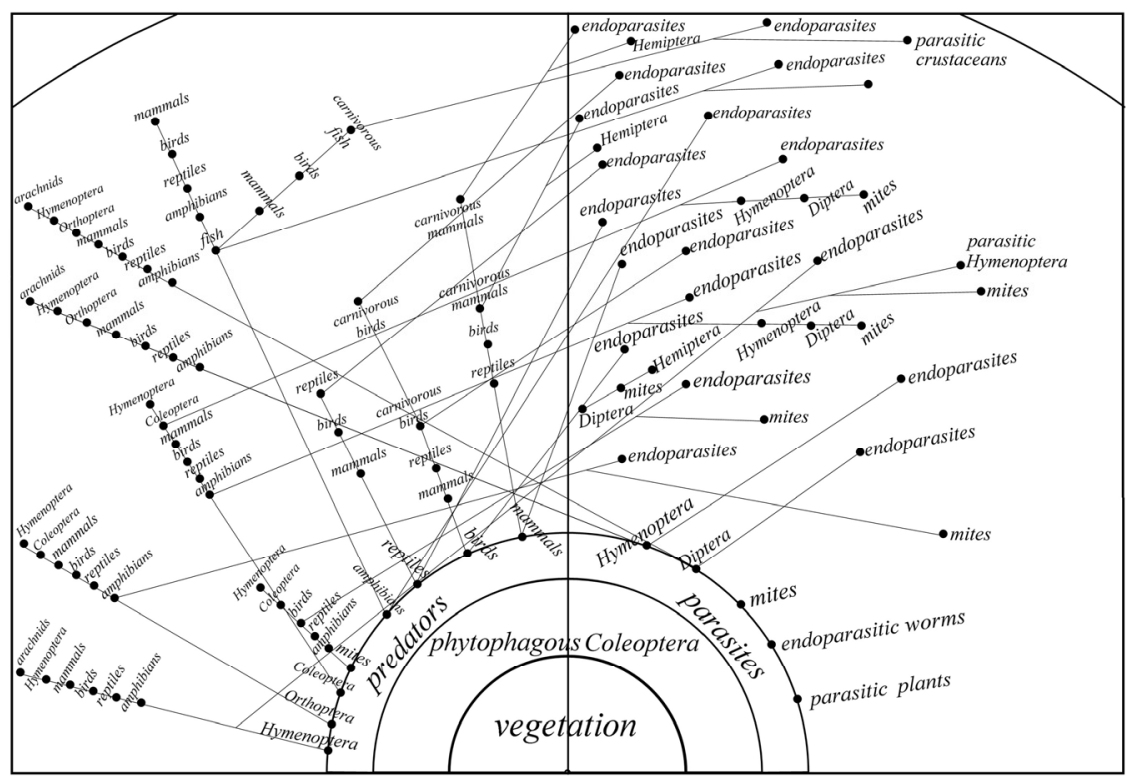

Figure 2. The first food-web graph reported in the literature, from Camerano (1880) (17). The graph was redrawn to improve readability. The structure is similar but species names were translated from Italian to English. (Adapted from Camerano, 1880) (17).

interactions was implicit in Darwin's (1859) (13) aforementioned description of forest succession, as well as in Möbius (1877) (20) definition of the biocoenosis. It was already expressed explicitly by Edward Forbes (1843) (21) when he described the change in species abundance and identity in animal communities of the Aegean Sea. What is apparently new with Camerano is the notion of a balance of nature resulting in an equilibrium in the densities of the component species, which is naturally re-established after a perturbation due to the abnormal growth of a species. This concept of equilibrium communities has had a huge influence in ecology $(22,23)$, and continues to be one of the big issues in this field $(24,25)$. For example, the classical work of May (1974) on the stability of model ecosystems is based on the assumption of communities being at equilibrium (26).

Second, the contribution of Camerano teaches us that the question of top-down or bottom-up control of communities was already a lively one 
more than one hundred years ago. Top-down control refers to a situation where regulation occurs predominantly through predators. A classical example is the sea otter which is able to prevent sea urchins from overgrazing seaweeds (27). If otters are removed from the system, sea urchins are able to completely deplete kelp forests. If this concept is correct, Camerano deduced that the removal of birds would be detrimental since they destroy insects which damage crops. Bottom-up control (or donor control) refers to a situation where prey (here plants) control the density of their consumers, while the consumers have little impact on their prey. In such bottom-up systems, birds would have little effect in destroying insects since the abundance of the latter is primarily determined by the availability of plant food, and not by their predators. Camerano's was apparently in support of an intermediate position: while he was assuming that animals develop in proportion of their available food, he also recognized that a perturbation in the number of carnivores could alter the abundance of herbivores and subsequently of plants. From this, it is apparent that Camerano foreshadowed the current debate on the importance of top-down versus bottom-up control of communities (e.g. ref. 28). He also cleverly introduced the idea of indirect effects cascading through a food chain. If species A is eaten by species B, and B is in turn eaten by species $C$, then $C$ will have an indirect positive effect on $A$. This idea was extended to higher trophic levels. It anticipated the models of population dynamics applied to lake communities found in contemporary literature (e.g. ref. 29). Finally, Camerano noted that an articulate answer to the question of useful and harmful species could only be attained when considering the interactions inside the whole community, and not simply between plants and animals. From these elements, one would guess that Camerano has had a vivid legacy in ecological thinking. He has not. Camerano's work was left unknown to ecologists until very recently $(30,31)$. For example, no citation to his work appears in an earlier contribution on the history of ecology (32), and the important concepts he developed had to be reinvented - a situation not uncommon in the course of scientific progress. In this vein, it is interesting to consider the work of Cajander, a Finnish ecologist who also conceived many modern concepts of ecology in the early years of the $20^{\text {th }}$ century, but was also forgotten (33). However, while Cajander's thoughts gave a central 
importance to species interactions in order to understand community organization, and notably why communities are at equilibrium, he apparently did not introduced a network representation.

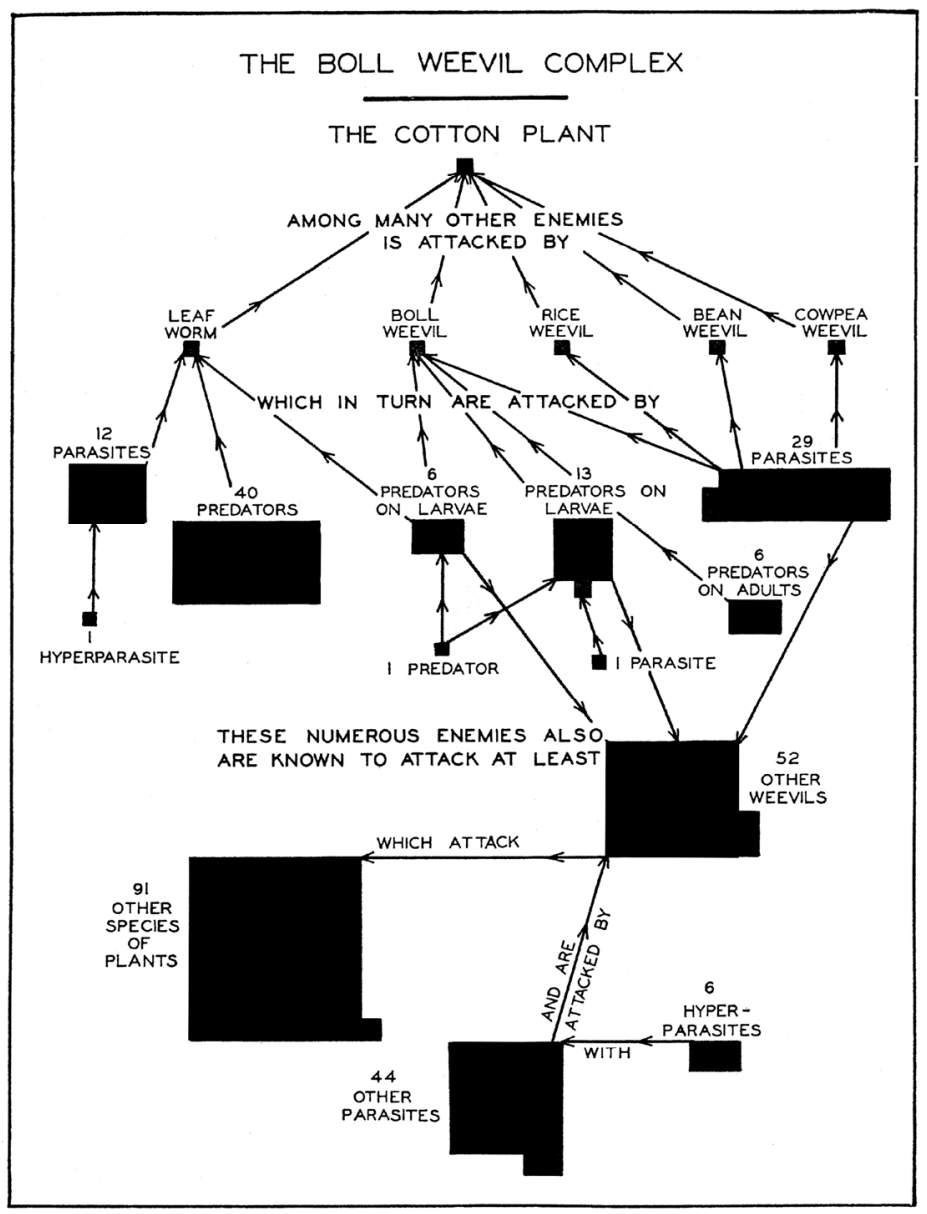

Figure 3. The food-web of the boll weevil, from Pierce et al. (1912) (34). Direction of arrows is from consumer to prey; numbers and size of boxes refer to the number of species in the group. (Reprinted from Pierce et al., 1912 (34), with permission from USDA.)

The second network oriented approach to an ecological problem only appeared 30 years later. It is due to Pierce, Cushman, and Hood (1912) who, similarly to Camerano's concern, were interested in a practical 
problem of agricultural relevance, the control of boll weevil populations, which caused economically substantial damages to cotton industry. They attempted to describe the predatory and parasitic interactions of the boll weevil as a web of interactions (Fig. 3). Allee et al. (1949) reproduced this figure in their chapter on the history of ecology because of its novelty and since it presaged much of the research of that time (32). It is interesting that one of the main conclusions of Pierce et al. is that the constellation of predators of the boll weevil has a high rank in the struggle against this pest, and that parasites could be introduced to improve its control. It is likely one of the first attempts to use biological control to enhance crop production. What is exemplary is the care in tackling this problem through an understanding of how player species are structured in a network of interactions. In the same epoch, a food-web graph was published by Shelford (1913), a pioneer of community ecology. It was however based on hypothetical data, and is thus not of great interest (35).

For many, the father of food-web ecology is Charles Elton, who analyzed in some detail the trophic interactions among the species inhabiting Bear Island, during the 1921 University of Oxford expedition to Spitsbergen (Fig. 4; refs. 36,37). Elton's contribution to modern ecology was essential. He described important concepts like the pyramid of numbers - the number of individuals decreases in higher trophic levels - and the food cycles, which is exemplified in Fig. 4 - the diagram traces the flows of nitrogen in the Bear Island community. He gave a strong impetus to a move from a descriptive ecology to a functional one: it is not enough to tally species in an ecosystem, one must know what they do. The food cycle is an illustration of the role of species in a community. Elton also pointed out the importance of allochthonous inputs in Bear Island, with most of the nitrogen coming from the sea. The role of such imports for the understanding of food-web structure has recently received a revived interest by the late Gary Polis and collaborators (e.g. refs. 38-40). He also cleverly noted the importance of body size on food-web organization, with consumers tending to be larger than their prey, and the opposite for parasites. This apparently trivial observation has nontrivial consequences for food-web structure, as will be seen later. Finally, it is very important to point out that Elton, in line 


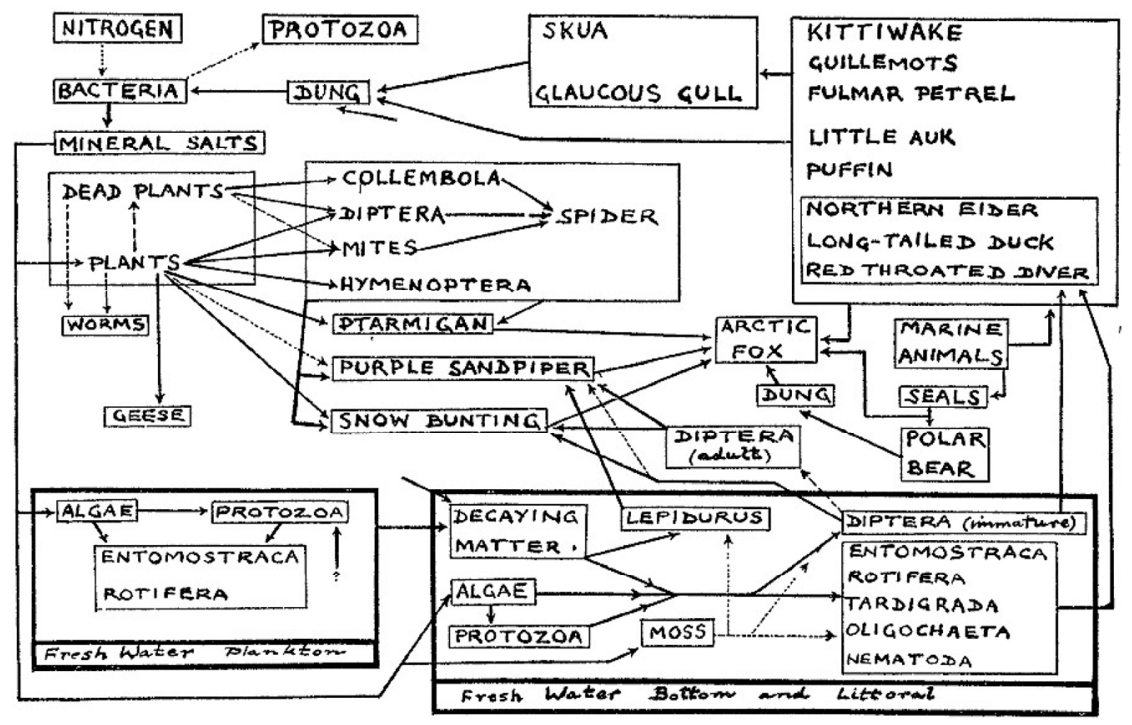

Figure 4. Diagram of the nitrogen cycle on Bear Island, from Summerhayes and Elton (1923) (36). Dotted lines are links that were not observed but probable. (Reprinted from Summerhayes and Elton, 1923, with permission of Blackwell Science Ltd.) (36)

with contemporary thinking, viewed food cycles as the regulatory process responsible for the fact that communities remain at equilibrium.

These three pioneering works all recognized the importance of studying the interactions between species in order to understand the organization and dynamics of communities. This was not in itself an originality among ecological thinking at that time. The novelty lies in the diagrammatic approach, specifically treating the community as a network. It is interesting to note that there was a debate in the nineteen thirties about the existence of a "balance of nature". A widespread view among ecologists was that of a "divinely determined stability, orderliness and predictability in natural systems" (41) - the balance of nature. Such a vision was reinforced by influential ecologists like Clements, who considered communities as behaving like autonomous super-organisms (42). The opposite view was taken by Gleason (1926) (43), who considered communities to be structured more by chance immigration events and individual selection. In the same line, Elton was also opposed to the concept of a balance of nature. He assembled data on mammals 
showing that their abundances constantly vary, with irregular amplitudes and periods (44). However, he was obviously not opposed to the fact that communities may reach some stable state. Indeed, Elton is famous for his list of empirical and theoretical arguments in favour of the positive relationship between complexity and stability in ecological systems (45). That more complex systems - in term of number of species, and number and strength of interactions - should be more stable than simpler ones was a paradigmatic view among ecologists in the fifties and sixties. May's (1974) challenge to this paradigm has triggered a bloom of new studies on ecological networks, as we will soon see; but we first go back to the first half of the nineteenth century (26).

There were apparently few studies of whole communities that used a network approach after Summerhayes and Elton's (1923) (36) description of the Bear Island food-web (e.g. refs. 46,47). These early studies represented a bold attempt to embrace the whole complexity of communities, with the aim of understanding their dynamical functioning. However, apart from their descriptive value, few generalisations came out of these works. Ecologists were simply not armed to analyze and extract information from these interaction networks.

\section{Energy-based approaches}

A major step was Lindeman's (1942) contribution to the understanding of community structure as governed by energetic constraints (48). Elton had observed that species occurred in quite discrete size categories, with larger ones typically being scarcer and eating smaller ones, thus forming a pyramid of numbers: the number of individuals decreases as one moves up in trophic levels. Why does such a pattern exist? This intriguing question was answered by Lindeman (1942) (48), who considered communities as systems that transform energy. Energy from sunlight is processed essentially through photosynthesis - with an efficiency of about $2 \%$ - to form plant biomass, which is eaten by the second trophic level - herbivores - in turn consumed by species at higher levels. Lindeman recognized that energy transfer from one trophic level to the other is inefficient $-10 \%$ as a gross estimate - and that this energetic constraint is a basic organizing principle of ecological systems. Elton's 
pyramid of numbers can be understood as a consequence of energy flow between trophic levels and of body size differences between predators and their prey.

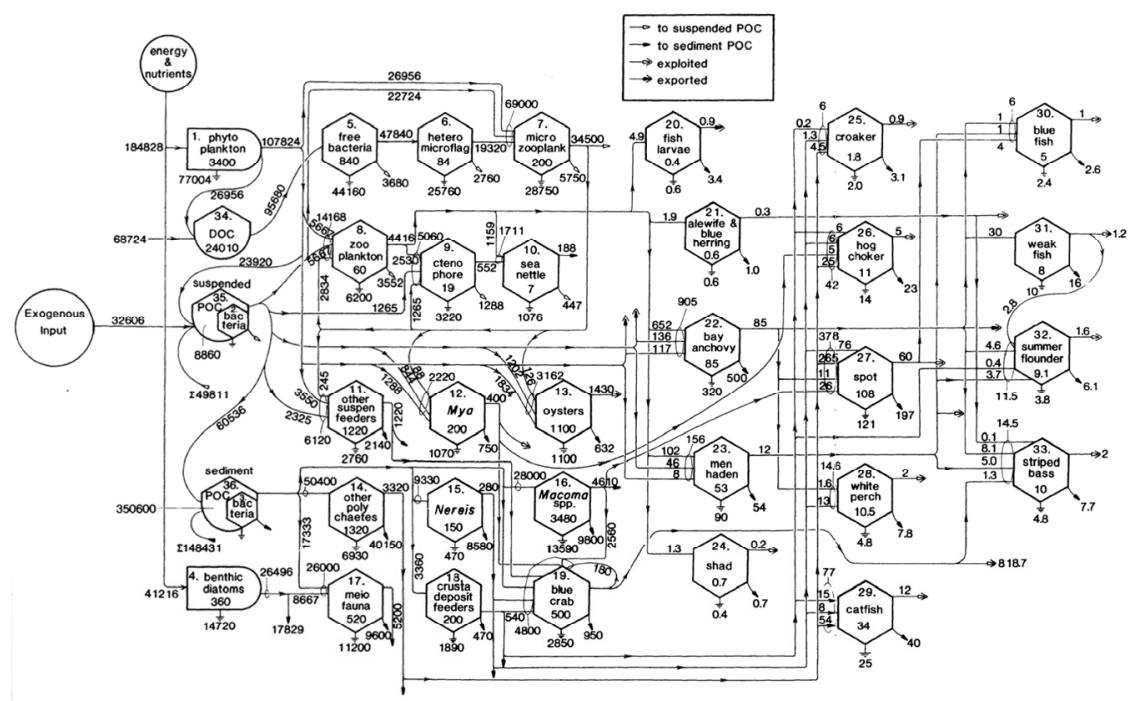

Figure 5. Energy flow network of the mesohaline area of Chesapeake Bay during summer (carbon flows in $\mathrm{mg} \cdot \mathrm{m}^{-2} \cdot \mathrm{summer}^{-1}$ ), from Baird and Ulanowicz (1989) (49). POC, particulate organic carbon; DOC, dissolved organic carbon; circles refer to external sources, "bullets" to autotrophs, hexagons to heterotrophic species, "birdhouses" to nonliving storages, and ground symbols to respiration. Number inside the boxes is the standing biomass in $\mathrm{mg} / \mathrm{m}^{2}$. (Reprinted from Baird and Ulanowicz, 1989, with permission of the Ecological Society of America.) (49).

Lindeman's breakthrough paved the way for an important school in ecology which considered energy flow through ecosystems (50). Brothers Eugene and Howard Odum initiated this approach by studying the impact of nuclear bomb tests on marine ecosystems, with the assumption that disequilibrium between productivity and respiration is an indication of an unsustainable system. These energy budget studies at the ecosystem level gained in popularity with the development of a formal symbolism aimed at graphically representing the flows of energy through the various actors of the ecosystem (see Fig. 5). The Odums developed an important body of ecosystem theory (51-53). Notably, Howard is 
famous for his thermodynamic view of ecosystems and the recognition that energy takes various forms when flowing through the ecosystem the concepts of transformity and emergy (53-56). One of the Odum brothers' prominent ideas is the view that ecosystems evolve toward higher levels of homeostasis, and consequently higher stability, through a combination of selection at the system level and evolution. They considered ecosystems as self-developing in terms of energy: species and interactions are selectively reinforced towards more efficient energy use at the system level. Recycling loops, providing nutrients back into greater production, are particularly important in this respect: they are naturally favoured since they are auto-reinforcing. Such loops, depicted in Fig. 6, are called "indirect-mutualism" (57); they are autocatalytic in the sense that an increase in activity of one node will consequently increase the activity of all nodes. This early view of self-organization and evolution at the ecosystem level may appear a courageous tenet in the 1960s. At that time most evolutionists dismissed any idea of group selection (58) in favour of individual selection, mainly because of the emergent conflicts between the various levels of selection (59). But schools of evolutionists and of system ecologists have largely progressed independently. It is interesting to note that evolutionists have recognized since the importance of selection at levels higher - and smaller - than the individual (e.g. refs. 60-63). Notably, that ecosystems are prone to selection has been demonstrated experimentally in artificial conditions (64). The recent development of the "extended evolutionary theory" (65),

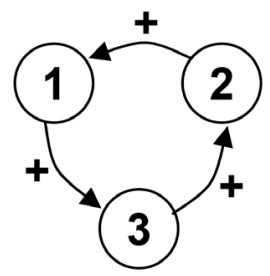

Figure 6. Example of indirect mutualism. Such configurations are autocatalytic loops. When embedded within a larger system, the species involved in such loops will be naturally reinforced. A simple biological example of such a loop is the system formed by the aquatic carnivorous plants Utricularia, which excrete on their surface exudates that are consumed by a periphytic community, in turn consumed by zooplanktons that close the loop when they are captured inside the hollow leaves of the plant. 
may in a way reconcile the Odum brothers' early ideas with current evolutionary theory. This new theory considers evolution not only as a one-way process with natural selection acting from the environment to the individuals, but as two-way process where selected individuals concomitantly modify their environment through "niche construction". The modified environment is bequeathed to the descendants, a case of ecological inheritance.

For the specific concern of network analysis, the Odums were not so much interested in the structure and architecture of the ecosystem networks, but on their global functioning in terms of energy processing. They used very global measures of ecosystem "health", for example the ratio of primary production to community respiration (52). However, they pioneered a holistic and systemic analysis of ecosystems, and instigated concepts that lie at the heart of current thinking in network research, notably self-organization. They are also the fathers of system ecology, a school that regrettably appears to be forgotten by many researchers in the field of network analysis. This school developed a strong and wide-ranging body of theory on ecosystem analyses (e.g. refs. 66,67). A multi-faceted account can be found in Patten and Jørgensen (1995) (68). The work of Ulanowicz $(69,57)$ is particularly relevant for the study of networks, where ecosystems are considered weighted networks: nodes are species (or functional groups), and links are biomass flows, typically expressed in milligrams of carbon per square meter and year $\left[\mathrm{mgC} \cdot \mathrm{m}^{-2} \cdot \mathrm{y}^{-1}\right]$; exogenous inputs, respiration, and exports are taken into account (see Fig. 5). Ulanowicz developed a suite of macrodescriptors of weighted networks based on information theoretical indices. It is outside the scope of the present chapter to review all descriptors here, but three particularly useful measures are worth mentioning. "Average mutual information" (AMI) is a measure of constraint in the network: a maximally connected system (all nodes are connected to all others) with links of equal weight has the minimum AMI - there is no constraint since biomass can flow everywhere (Fig. 7a); a simple chain connecting all nodes will have maximum AMI - biomass is constrained to follow this route (Fig. 7b). For a given ecosystem, a way to scale this information measure is to multiply AMI with the total system throughput (TST, the sum of all flows). This yields a quantity 
called the "ascendency". A core hypothesis of system ecology is that evolving systems naturally gain ascendency. According to system ecologists, the driving forces are autocatalytic loops - indirect mutualism (Fig. 6) - which will necessarily enhance the importance of flows comprised in their paths. This asymmetric force will favour links to the detriment of others, yielding more and more articulated networks (of the kind of Fig. 7b). Ascendency is a macro-descriptor of ecosystem development that is based on information on the weighted network structure of the ecosystem, with weights corresponding to flows of biomass between species. Another intriguing descriptor of food-web structure is the so-called "effective connectance" (70). In food-web ecology, connectance is a measure of the density of links in a network. Unfortunately, it possesses different definitions (71), the most widely used being called directed connectance, the number of observed links $\mathrm{L}$ divided by the number of possible links (72). The number of possible links is the number of species (or nodes) squared, $\mathrm{S}^{2}$ (thus, directed connectance is equal to 1 in Fig. 7a, and to 0.2 in Fig. 7b). However, directed connectance considers all links as equal and thus disregards the variation in flow within weighted networks. The effective connectance, which is based on the conditional entropy of the system, is a way of expressing the density of links in weighted networks. It is a fundamental measure that has fostered interesting hypotheses on the structure and dynamic of communities (73). Ascendency and effective connectance are two examples of descriptors of weighted networks developed in system
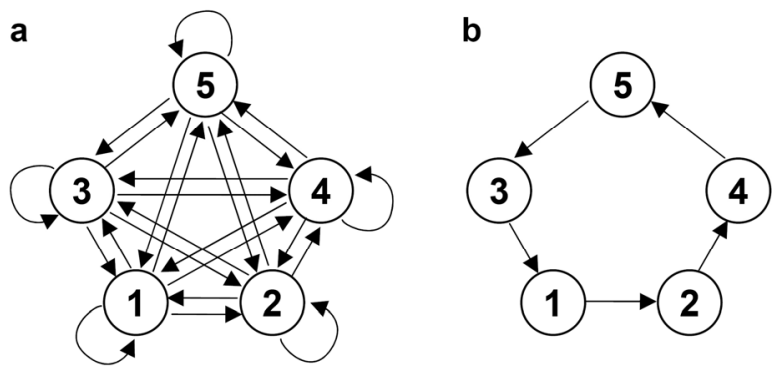

Figure 7. Two extreme configurations of a five compartment network. In a, there is no constraint where energy can flow in this maximally connected network, while the route is unique in $\mathbf{b}$. 
ecology. Other measures derived from information theory have been devised to describe different aspects of ecological networks (69), and they also have a strong potential to prove very useful in future analyses of various kinds of weighted networks.

\section{Complexity and stability}

It is interesting to note that the school of system ecology - that dealt mainly with ecosystems - has developed quite independently from "classical" community ecologists. For example, Paine's (74) seminal work on food-web complexity does not cite any of Odum's works, nor does Morin (3) give any reference on system ecology in his textbook on community ecology. This paucity of interactions between the two communities may appear surprising when one traces back to the source of the interest in network analysis. As described above, the Odums paved the way for system ecology, but Eugene (51) is also the author of a proposition that, I believe, lies at the heart of the current interest in network analysis by community ecologists. Odum (51) suggested that, in a community, the amount of choice (in other words, of alternative paths) a quantum of energy has in going from autotrophs to higher trophic levels is a measure of community stability. This statement was used by MacArthur (75) in a very influential paper on the link between complexity and stability in food-webs. In fact, this link between the static and dynamic properties of a community was made so strongly that the number of connections in a food-web was taken as a direct measure of stability - without regard to any yearly observations of the abundances of species. This statement was a strong incentive for the view that complexity begets stability - the "conventional wisdom" among ecologists in the 60s (76). Apart from this reasoning based on the density of links in networks, Elton (45) provided a suite of arguments in favour of the complexity-stability positive relationship. MacArthur's (75) contribution gave a strong impetus for the study of the effect of diversity on stability in real communities. It is worth mentioning that MacArthur suggested a function to describe the stability of a network, and used Shannon's famous measure of information for this purpose. However, the application of Shannon's formula in this context has apparently been 
forgotten by most community ecologists, while it has been widely used by system ecologists. The vast majority of ecological studies using Shannon's formula applied it to measure the species diversity of communities (77), and not to interactions between species. Two reasons can explain this shift: first, MacArthur deduced that greater stability could be achieved with more species, given that the number of prey per species remains constant, and second it is much more difficult to quantify the magnitude of interactions - MacArthur remained very vague on this point - than the importance of species, readily given by their abundance.

Few field studies of ecological networks were published in the years after MacArthur's (75) paper (e.g. refs. 78,79). Among them, a very important contribution is that of Robert Paine (74) on the study of foodwebs in marine rocky intertidal zones along a latitudinal gradient. This work is noteworthy because it provides a precise estimation of the relative importance of interactions - in terms of the frequency of predation acts, and of the energy involved in each link. The vast majority of subsequent work on food-webs does not include information on the importance of trophic interactions, the omission of which has hindered the discovery of robust patterns in the structure of food-webs (80). Another unusual feature lies in the experimental approach taken by Paine. By removing the top predators (starfishes), he was able to show that the community became simpler because one of the prey species was able to out-compete the other species and occupy the available space. Even species not preyed upon by starfishes were affected by their removal, an experimental demonstration of an indirect effect called keystone predation (see below). Also, when comparing tropical vs. temperate systems, Paine suggested that the stability of annual production would allow more predators to be supported, thus increasing the diversity of the whole system. Though this argument is not directly related to MacArthur's assertion that more complex systems are more stable, it is certainly not incompatible with it. It remains that ecologists in the late 1960s were unanimous about the positive relationship between complexity and stability.

One of Elton's (45) arguments in favour of this relationship was that simple two-species predator-prey models are inherently unstable. Of course, this argument says nothing about the stability of models with 
many interacting species, but obviously assumes that they should be inherently more stable. It is this assumption that has been challenged by the seminal work of May $(81,26,82)$. He found that, on the basis of mathematical models, randomly assembled systems will remain stable if the product of average interaction strength $\alpha$ and the square root of $\mathrm{S} \cdot \mathrm{C}$ remains smaller than one, with $S$ the number of species in a food-web, C the connectance, that is the total number of trophic links $\mathrm{L}$ divided by the number of possible links $\left(\mathrm{S}^{2}\right)$, and $\alpha$ the average interaction strength, a measure of the magnitude of the effect of the abundance of one species on the abundance of another. This is known as "May-Wigner stability criterion" $(\alpha \sqrt{S C}<1)(83)$. In other words, assuming a constant $\alpha$, foodwebs will become unstable with an increase of either species diversity, number of interactions, or both. This discovery was a real bombshell. It is important to recognize the assumptions of May's analysis: the system is at equilibrium, and only local stability is assessed by the analysis; the interactions between species are random, i.e. the network is a random graph: any species can interact with any other, with probability set by the value of connectance $C$; the interaction strength between species is set by a random number drawn from a normal distribution with mean 0 and standard deviation 1. May himself was certainly the person most aware of the ecological limitations of his criterion. Few results in ecology have elicited so many critiques, and fostered such a wealth of studies. Empirical ecologists have complained about the irrelevance of May's analysis for real systems, and Polis (84) hoped that descriptions of real food-webs would pound the final nail into the "coffin of May's paradox". Theoreticians have challenged the criterion itself, and Cohen and Newman (85) showed that the criterion was not as general as originally thought (but see refs. 86). Whatever the critiques, it is indisputable that the huge merit of May's study was to force ecologists to think deeply about the complexity-stability question, and this was the starting point of a fruitful body of research in different disciplines. One can recognize at least four interdependent research directions in which ecologists have ventured to answer this question.

First, May's analysis is purely theoretical, and ecologists have conducted since many experiments to test the relationship between diversity and stability. A major initiator of this kind of research agenda is 
David Tilman, who started in the early 1980 s a long-term field experiment with plants aimed at answering if diversity does affect ecological functioning in term of biomass production (87-90). Europeans researchers set a similar kind of experiments in eight countries (91), and experiments were also conducted in laboratory controlled settings (92). The results raised controversy in their interpretation $(93,94)$, a major difficulty being to disentangle the effect of diversity per se and the statistical effect of selecting by chance a plant with a high productivity, such a probability being of course higher with higher number of species. This again fostered theoretical efforts to reconcile the opposing views $(95,96,97)$. The main result can be summarized as follows: within an ecosystem, plant diversity is positively correlated with stability at the community level (higher yield), but not always with stability at the population level $(98,25)$. This positive relationship is due to the complementarity effect of diversity (i.e. to a better utilization of all resources through finer resource partitioning and/or positive interactions), and not to the selection effect (i.e. higher chance of having a strong competitor in the plant mixture). However, it must be noted firstly that the kind of stability envisaged in such experiments is quite different from the stability envisaged by Elton, MacArthur or May, and secondly that these experiments concerned mostly only one trophic level - plants - and made no explicit reference to the structure of interactions between the species. In this respect, the connection to ecological networks is very loose. It is also worth noting that the relationship between diversity and ecosystem functioning is not as straightforward when higher trophic levels are taken into account $(99,100)$.

The experiment of Fagan (101) is an intriguing study linking stability and the structure of trophic interactions in natural food-webs. Fagan explored the effect of omnivory on stability in natural patches dominated by two species of plants on Mt St-Helens. He manipulated the level of disturbance through aphicide application, and of omnivory by adding or removing wolf spiders (Pardosa sp.) and damselbugs (Nabis sp.), the former are omnivorous, the latter not (Fig. 8). According to May's (81) findings, omnivorous species should destabilize the system since they increase the level of connectance. Other theoretical works supported this idea (102-104). But Fagan found the opposite: increased levels of 
omnivory tended to stabilize the dynamics of the community. Other experiments in microcosms supported this result $(105,106)$. In all, we see that experimental challenges of May's findings tend to demonstrate that complexity increases stability in communities.

A second direction of research following May's contribution is the exploration of the influence of interaction strength for stability. The notion of interaction strength is deeply entwined with classical LotkaVolterra models of species interactions, where the effect of species $i$ on species $\mathrm{j}$ is modelled as a simple law of mass action, i.e. the effect is proportional to the product of both abundances times interaction strength $\alpha_{\mathrm{ji}}$ (Fig. 9). Such a modelling approach is unsound for ecological systems as it leads to nonsensical situations, for example a single predator $\mathrm{j}$ in presence of a huge number $\mathrm{N}$ of prey i should consume alone $\alpha_{\mathrm{ji}} \mathrm{N}$ prey, without being satiated. This has generated a large body of mostly theoretical researches on so-called functional responses, i.e. the number of prey eaten per predator, and to a much lesser-degree, on numerical responses, i.e. the number of predators produced per prey consumed, with sometimes heated debates (107-112). May's approach accommodates any form of response, since local stability analyses are evaluated close enough to the stable point that a linear response can be assumed.

However, what appears crucial in May's approach for the negative relationship between stability and diversity is the assumption that interaction strengths between species comprised in a community do follow a normal distribution, with mean 0 and standard deviation 1 . In fact, it has been found that the distribution of as plays a major role for the stability. The first study pointing out this possibility is Yodzis' analysis of the dynamics of systems where the structure and the strengths of interactions were derived from the observation of real ecological systems (113). Yodzis found that, compared to random systems, such biologically possible ones were much more stable. However, it was not clear why. Answers awaited the study of McCann et al. (1998), Berlow (1999), and Neutel et al. (2002) (114-116). McCann et al. (1998) used nonlinear models of simple systems where interactions strengths between species were allowed to vary (114). It was found that weak interactions 


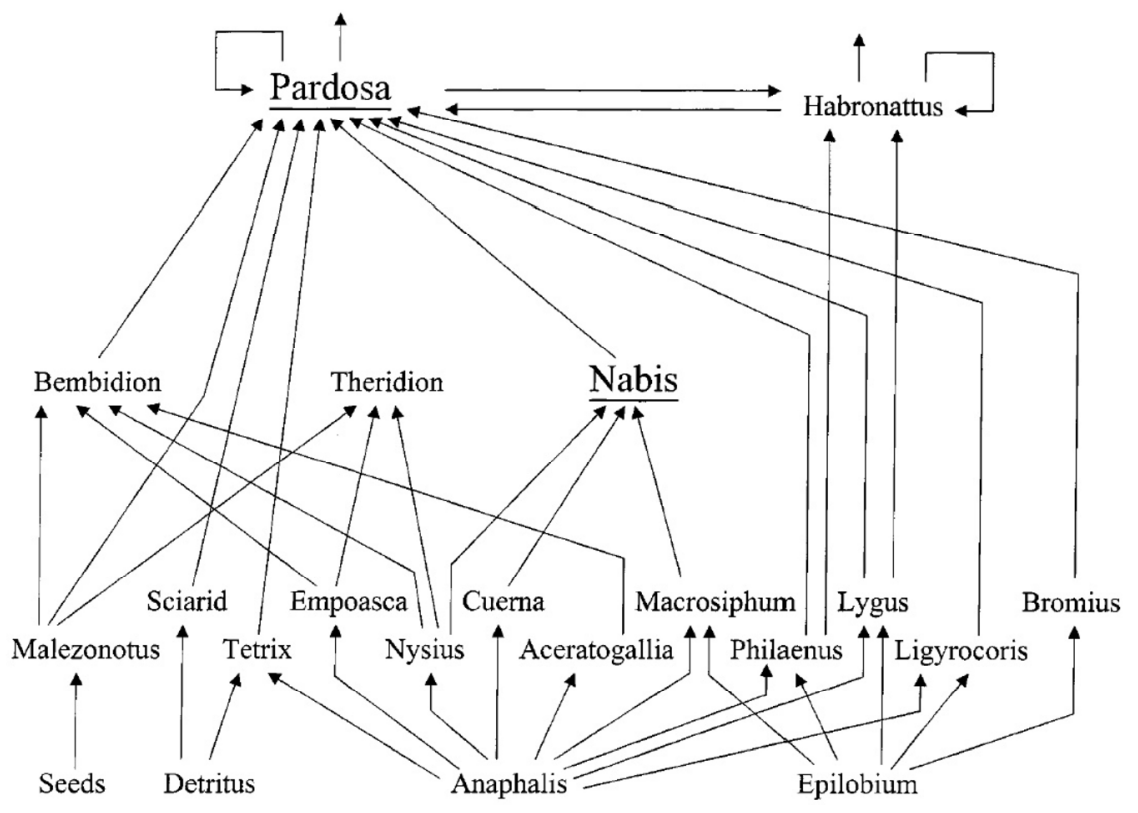

Figure 8. Feeding relationships among arthropod species in the Mount Saint Helens blowdown zone (Fagan 1997) (101). Pardosa is a generalist predator and Nabis a specialist one. Manipulations of their abundances and application of a disturbance to the system revealed that the generalist species had a stabilizing effect on community dynamics. (Reprinded from Fagan, 1997 (101), with permission of the University of Chicago Press.)
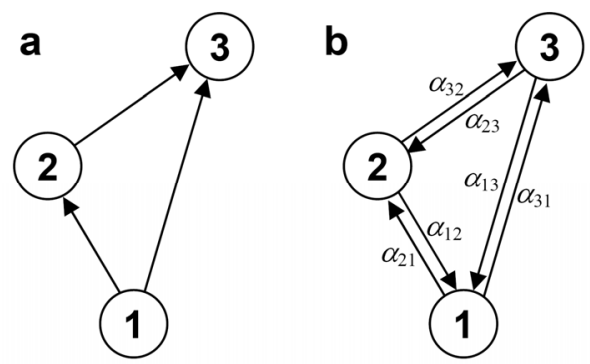

Figure 9. A food-web graph depicting the flows of biomass (a), and the corresponding graph with interaction strengths (b). In the case of a trophic interaction between a consumer $j$ and a prey $i, \alpha_{i j}$ is negative and $\alpha_{j i}$ positive. Note that this graph possesses two loops of size three $\left(\alpha_{31}-\alpha_{23}-\alpha_{12}\right.$ and $\left.\alpha_{13}-\alpha_{21}-\alpha_{32}\right)$, configurations explored in Neutel et al. (2002)(116). 
have a stabilizing effect because they act to dampen oscillations between consumers and prey, thereby allowing higher densities and consequently diminishing the probability of extinction. Berlow (1999) (115) additionally found that weak interactions are proportionately extremely variable in strength, and suggested that this feature could enhance spatial variability which is known to promote the persistence of species (117121). More recently, Neutel et al. (2002) (116) concentrated on loops in food-webs (see Fig. 9), which are known to have a destabilizing effect. They found that long loops contain in fact many weak links, which stabilizes the dynamics of the system. All these study show that the presence of many weak links stabilizes food-web dynamics and generates a positive relationship between complexity and stability. Importantly, the presence of many weak links is consistent with observations of real systems (122). Robert Paine (122-125) has initiated the functional description of food-webs. He argued that a purely topological description of the trophic interactions between species can only bring little information on the functioning of a system, and that quantitative information on biomass flows is as well not satisfactory (Fig. 10). The key problem is that both such descriptions provide no information on interaction strengths. It is consequently not possible to link the structure of a system with its dynamical behaviour. Paine advocated instead the use of experiments to estimate interaction strengths between species by a suite of removal experiments (122). This approach has the advantage of the adequacy of measurements with system functioning, but is hardly feasible in species rich systems (126-128). In any instance, this discussion highlights the difficulty of documenting interactions between species in a way that ties theory and empirical studies.

Third, May's (1972) study is based on the assumption that communities lie at equilibrium, that is, that the abundances of all species remain constant - a point in the phase space (81). Local stability analyses evaluate what happens when abundances are displaced close to this equilibrium point; the dynamics is locally stable when the trajectory goes back to the equilibrium point, and unstable if it diverges. This assumption reminds the early ideas of a balance of nature, with the abundances of species adjusting to each other to attain a precisely fixed 
state. However, ecologists have been more and more suspicious with this early belief about community dynamics, and became aware that the perspective of non-equilibrium dynamics was ecologically sensible. Species abundances show fluctuations which are driven by biotic and

a

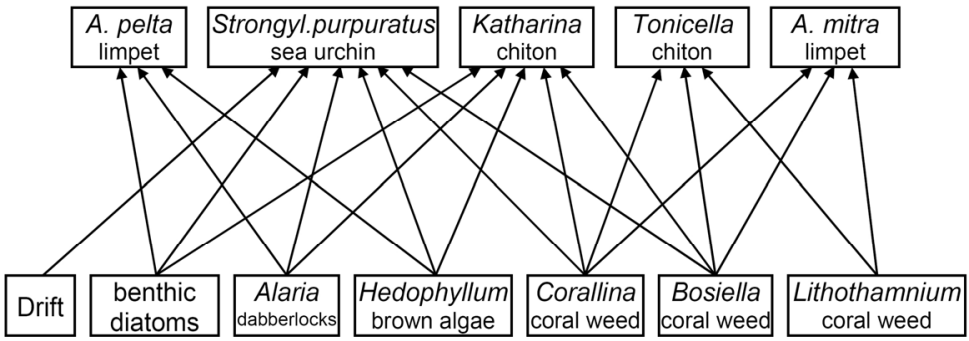

b

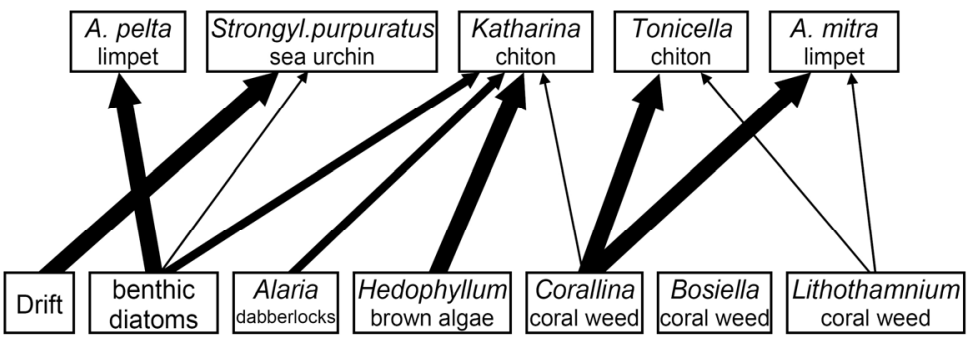

C

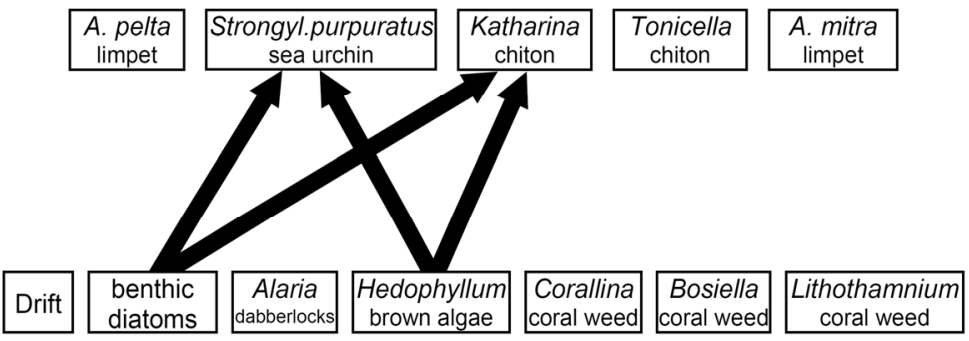

Figure 10. Three ways of looking at interactions in a food-web (Paine 1980) (122). (a) a purely topological web indicating the trophic interactions; (b) the energy flows provide quantitative information on the importance of flows, but not necessarily on the functional organisation of the community; (c) the functional web (or interaction web) is based on controlled manipulations measuring the effect of the removal of a consumer on the abundance of prey. It can reveal that weak interactions in term of biomass flow may have strong dynamical effects. (From data in Paine 1980) (122). 
abiotic interactions. Studies relaxing the equilibrium assumption have flourished (e.g. refs. 129,130,114,131), and appropriate measures of stability had to be used (103). In general, it was found that population fluctuations can strongly promote the coexistence of species (25). In this respect, an intriguing study links non-equilibrium dynamics and network structure in model systems (132). Michalski and Arditi found that the structure of a food-web was typically much simpler in terms of connectance under equilibrium assumptions than under non-equilibrium dynamics (Fig. 11). The way dynamics is modelled does not only affects species diversity, but also the structure of connections between species. It must be noted that this quest for the consequences of non-equilibrium dynamics has largely been restricted to theoretical studies. Few analyses of the dynamics of real communities have been undertaken (e.g. 133135). They confirmed the view that communities do not lie at equilibrium.

Fourth, a strong assumption in May's analysis is that connections between species are random. This can be perceived as a null hypothesis for the architecture of real food-webs. Ecologists have searched for regularities in the topological structure of food-webs, found that real networks are not random graphs, and developed models to explain these patterns. This theme is intimately linked to network structure and will be expanded in some length in the forthcoming section.
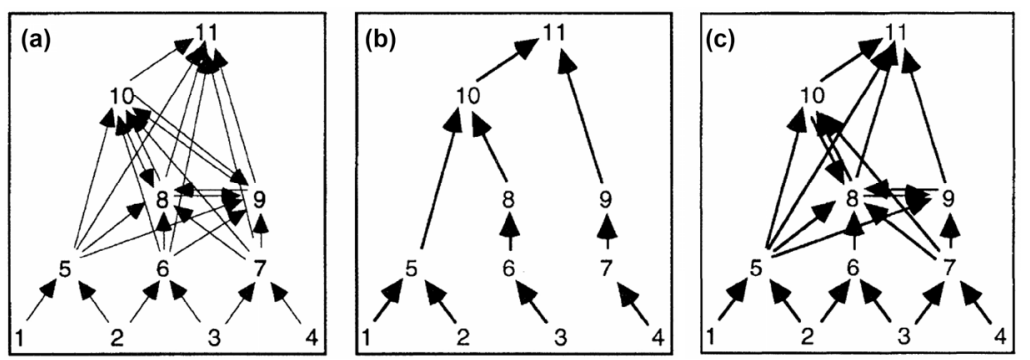

Figure 11. Interactions in a food-web in an equilibrium and a non-equilibrium context (Michalski and Arditi 1995) (132). (a) The potential interactions allowed by the dynamical model studied; (b) effective food-web structure realized at the equilibrium; (c) possible food-web structure under non-equilibrium dynamics. (Reprinted with permission from Michalski and Arditi, 1995, (132) Proc. R. Soc. B 259, 217-222). 


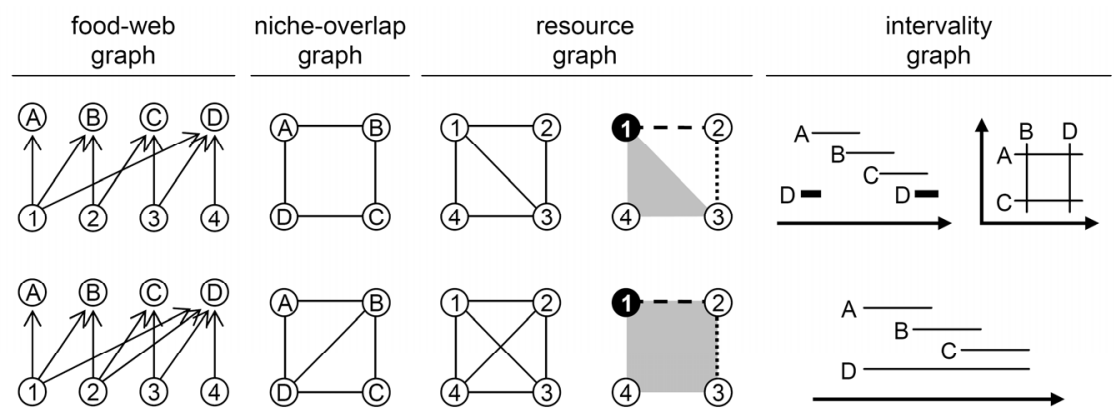

Figure 12. Example of two food-web graphs and the corresponding niche-overlap, resource, and intervality graphs. The food-web graphs depict the flows of biomass between prey ( 1 to 4 ) and consumers (A to D). The niche overlap graph is constructed by linking consumers that share at least one prey in common. The resource graph is constructed by linking prey that share at least on consumer in common; predators can be superimposed on this graph, giving rise to a picture of the niche of the whole community (consumer $\mathrm{A}$ is a point above prey 1; consumers $\mathrm{B}$ and $\mathrm{C}$ are the dashed and dotted lines, respectively; consumer D is the grey triangle - above - or the grey square - below). The interval graph is built by representing consumers as segments that overlap if they share at least a prey. The above food-web graph produces 1) a non-rigid (also called non chordal, or non triangulated) niche overlap graph: consumers form a circuit of four points without a chord shortening the circuit, as in the below niche-overlap graph. The above resource graph contains a topological hole between prey 1,2 , and 3 . The above food-web graph is non-interval: it is not possible to arrange the consumers as segments along a single dimension (it is not possible to place D in this example); two dimensions are needed. Analyses of early collections of food-webs revealed a strong excess of rigid nicheoverlap graphs, of resource graphs without holes, and of interval food-webs (as in the below food-web)

\section{The topological structure of food-webs}

The pioneer in the search for topological regularities in food-webs is Joel Cohen. He was the first researcher to assemble a collection of food-webs - from the literature - and to explore the regularities found in such data. He was also the first to confront these observations to theoretical models of food-web structure $(136,137)$. Cohen explored how the niche structure of communities could be deduced from information on food-web structure. For this purpose, he developed so-called niche-overlap graphs (Fig. 12, 13), and applied graph theoretical tools to analyze them. The niche-overlap graph is built from information of the food-web graph to 
obtain a representation of the structure of exploitative competition (that is competition for resources, in the present case trophic sources) within the community. Simply, an edge is drawn between species that consume at least one species in common, and are thus potentially competing for that prey. This new graph is by itself very informative, but Cohen went one step further by exploring their intervality (Fig. 12). The discovery was intriguing: most niche overlap graphs of the dataset were found to be interval. The biological consequence is that it should be possible to arrange all species along a single niche dimension. The idea that trophic resources within a community could be mapped on a single dimension was certainly a surprise at that time, contrasting with the view of a multidimensional niche $(138,139)$. Cohen offered some possible explanations of this pattern, but the prevailing one was offered by Lawton and Warren (1988) (140) : this single dimension could simply reflect the body size of the prey.

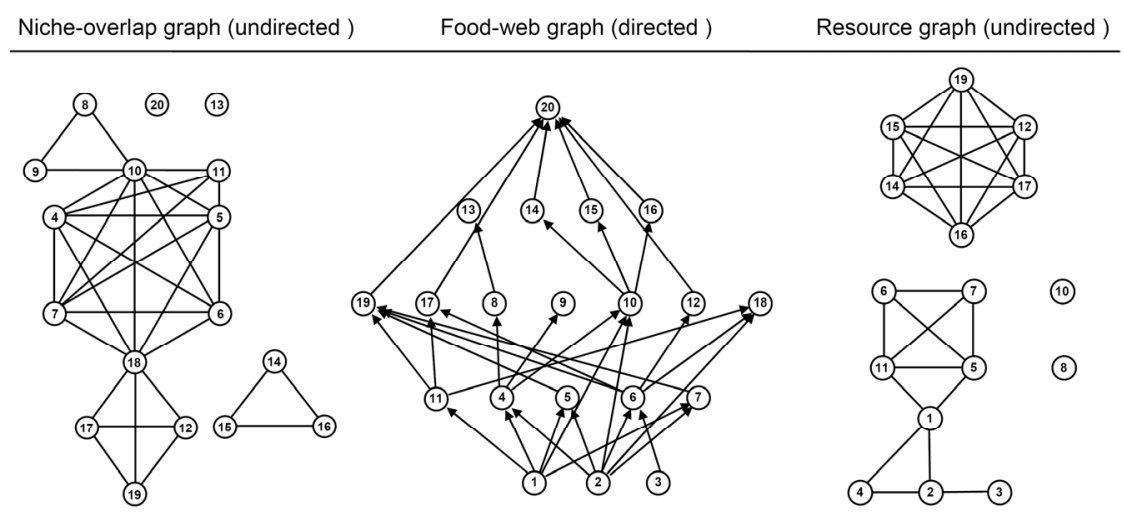

Figure 13. Food-web graph (centre) of the Narraganset Bay and their derived nicheoverlap and resource graphs (data from ref. 143). The niche-overlap graph provides a representation of the competitive interactions for shared resources between the consumers. The resource graph can serve as a representation of the communal niche (see Fig. 12), but also provides information on so-called apparent competition (see Chapter 6 on indirect effects). Note that niche overlap and resource graphs are undirected. Species are: 1. flagellates, diatoms ; 2. detritus ; 3. macroalgae, eelgrass ; 4. Acartia, other copepods ; 5 . sponges ; 6. benthic macrofauna and infauna ; 7. clams ; 8. ctenophores ; 9. meroplankton, fish larvae ; 10. Pacific menhaden; 11. bivalves ; 12. crabs, lobsters ; 13. butterfish ; 14. striped bass ; 15. bluefish ; 16. mackerel ; 17. other demersal species ; 18. starfish ; 19. flounder ; 20. man. 
If predators consume a set of prey that are restricted to a range of prey sizes, and that they consume all prey within this range, then a single niche dimension is sufficient. This is a nice example of the discovery of a non-intuitive constraint on food-web structure thanks to network analysis. It paved the path to further studies, notably on static and dynamical models of food-webs (141-143).

The research on food-web graphs was pushed one step further by Sugihara. First, he developed a different way of representing niche space from food-web information. He noted that Cohen's (137) niche-overlap graph was lacking the multidimensional portrait suggested by the Hutchinsonian niche, and proposed to use instead so-called resource graphs (Fig. 12, 13). The resource graph is an inside-out version of the niche-overlap graph: prey that share at least on predator in common are linked by an undirected edge. The interest of such a graph is that it is then possible to superimpose the consumers as simplexes (Fig. 12). This gives rise to a solid "tinker-toy" model of the niche of the whole community where prey are vertices and consumers polyhedral structures. These polyhedra have dimensions $n-1$, with $n$ the number of prey categories, which preserves the multidimensional flavour of the niche. Sugihara pursued by exploring regularities in resource graphs from a collection of real food-webs (data from Briand 1983) (144). He concentrated on the presence or absence of topological holes in resource graphs, and on the rigidity (also called chordal property, or triangulation) of niche-overlap graphs (see Fig. 12). Rigidity is a property of graphs that is closely related to intervality - all interval graphs are rigid, but the contrary is not true - while there is no necessary connection between rigidity and absence of holes. Sugihara found that most analyzed communities were rigid and lacked topological holes, in contrast to randomly constructed matrices. In other words, the niche space of communities is densely packed. This mere result led Sugihara to postulate a simple assembly rule for food-webs: new species added to a community must compete within a single guild (that is, a group of consumers sharing similar prey), and is prohibited to bridge two or more guilds. This simply means that it is not possible for an incoming species to join two guilds say of insectivores and of nectarivores. If this rule is respected, rigidity and lack of topological holes are granted. This rule 
can broadly reflect an invasion process acting at an ecological time scale, or a speciation process acting at evolutionary time scale. It gives rise to hierarchically structured communities, which can be represented by dendrograms representing phylogeny or niche overlaps, where more and more similar species are grouped together in a tree-like manner. Interestingly, this line of reasoning was successfully applied to models of species abundances in taxocenes $(145,9)$. Both works of Cohen and Sugihara are very compelling examples of how network analyses can shed new light on non-trivial ecological processes (146).

Food-web graphs themselves - and not derived niche-overlap or resource graphs - have also elicited a wealth of studies to uncover regularities in their structure. Again, Joel Cohen is a pioneer in this undertaking $(136,30,147)$. Food-web graphs are complex objects, and descriptors were devised to extract ecologically meaningful information (for a list of descriptors, see e.g. Yodzis 1989 (10), or Bersier et al. 2002 (148). As seen previously, individual food-webs appear complex and variable. However, first collections of large numbers of webs have yielded simple and intriguing patterns. These collections are those of Cohen (1978) (137), Briand (1983) (144), Sugihara et al. (1989) (149), and Cohen et al. (1990) (143). The most important of these patterns are the following $(140,180,104)$ : 1) food chains are typically short and consist of five or fewer trophic levels $(103,149,143)$; 2) connectance declines as species number increases in a way that the product of connectance and species number is roughly constant $(149,103,150,30,151)$ - this is equivalent to a constant link density (L divided by S); 3 ) the fraction of top species, (i.e. having no predator), of intermediate species (having prey and predator), and of basal species (having no prey), and the fraction of links between top and intermediate, top and basal, intermediate and intermediate, intermediate and basal species are scale invariant: they stay roughly constant across a variety of webs spanning a wide range in the number of species they contain $(147,149,143,152)$. These regularities were coined 'scaling laws'.

However, critics of food-web theory argued that such generalisations were artefacts due to the poor quality of the data sets (e.g. $150,124,153,154)$. Much of these data on food-webs were not gathered by the original investigators with the intention of producing realistic 
food-webs, but were most often provided as accessory information on the global structure of the studied systems. The lack of quality and uniformity in these early food-web collections is striking. Typically, "species" in higher trophic levels are resolved at the species level (e.g. fishes), while those in lower levels are crudely categorised (e.g. zooplankton, see Fig. 13). Following these criticisms, food-webs designed specifically to represent the full complexity of ecological systems were assembled (154-167,14). Indeed, these high-quality data challenged the validity of the previously recognized generalizations. The least robust property appeared to be the link density. It was soon proposed that a power law may be a more accurate description for this property $(168,143,24)$, and all recently compiled collections of foodwebs do not uphold the scale invariance for this property $(169,156,170,152,72,160)$. This led Martinez (1992) (72) to hypothesize that the directed connectance $\left(\mathrm{L} / \mathrm{S}^{2}\right)$ was the scale-invariant measure of food-web structure, and not the link density. Analyses of single highly resolved webs $(154,153,157,158)$ revealed values for the food-web properties that were not consistent with those reported from earlier studies: e.g. the link density was much higher, the fraction of top species much lower, and the various measures of chain length were found to be much larger. Most analyses of collections of food-webs produced results that diverged from the 'scaling laws': the properties varied with scale $(156,160)$. This led Martinez and Lawton (1995) (171) to put forward that the scale dependent hypothesis was more successfully predictive and precise than the old paradigm of scale invariance (see also next Chapter). Apart from this line of evidence based on the scaling properties of foodwebs, the recognition that food-webs were more complex than previously thought arose from increasing knowledge of feeding biology, and from recognition of the importance of additional trophic pathways (detrital channel, allochthonous inputs, life-history omnivory, or cannibalism) compared to those traditionally depicted by the trophic level ideal $(156,153,85,38,172)$. This complexity does not fit into the classical view of the trophic level concept, which led Polis and Strong (1996) (173) to question the usefulness of this concept, and to propose a new model that accounts for the full complexity of natural systems. 
Independently of this debate about the scaling behaviour of food-web properties, the importance of temporal resolution in the construction of food-webs was pointed out $(174,155,175,176,159,161)$. It was generally noted that food-webs sampled over specific periods of time produced values for the properties that were very different (especially for the link density) from those obtained with cumulated versions of the same webs. Since all species and links observed over the complete study period are never present on any particular sampling date, time-specific webs provide greater realism. For example, Schoenly et al. (1996)(177) studied the impact of insecticide in rice-plantation food-webs: cumulative versions of sprayed and unsprayed webs revealed no between-treatment differences, while time-specific webs before, during, and after spraying revealed classic examples of secondary pest resurgence and early-season losses of natural enemies over the spray interval.

Another important factor affecting our perception of the structure of food-webs is the degree of sampling effort used to document the webs. Goldwasser and Roughgarden (1997)(178), and Martinez et al. (1999) (166) found that most food-web properties were highly sensitive to this sampling effect. Bersier et al. (1999) (80) went one step further by showing that inherently scale-dependent systems could appear scaleinvariant when sampled with a low intensity. This result reconciled the opposite view on food-web structure, since it gave an explanation for the scale-invariance observed in early collections of food-webs, which were sampled with a low level of details. More importantly, this result revealed a basic problem with high-quality food-webs: such food-webs incorporate trophic links with huge differences in their importance in term of biomass flow. High quality data typically include some very strong links, and a lot of links of intermediate and low importance. Yet, food-web ecologists most often disregarded this variability and treated all links as equal (Fig. 14). This calls for a quantitative rather than a qualitative approach of food-web structure. Quantitative descriptors of weighted networks have been devised since $(148,179)$, and preliminary results show that food-web structure is indeed scale-dependent, with most descriptors having nonlinear relationships with species richness (179). 
Recently, new methodologies to analyze the topology of food-webs have yielded extremely interesting results (see Strogatz 2001 (181) for a review). They are partly borrowed from analyses of the robustness of communication networks like the Internet (e.g. ref. 182), which have a scale-free structure - that is, most nodes have few links and few nodes have a large number of links.
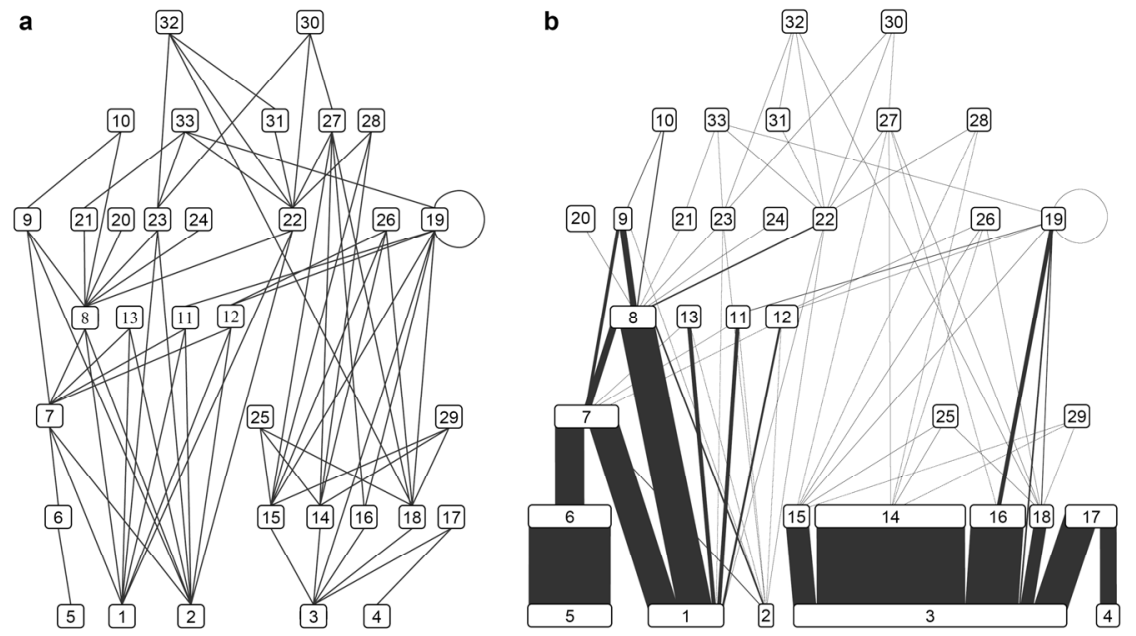

Figure 14. (a) Qualitative and (b) quantitative representation of the food web of Chesapeake Bay mesohaline ecosystem (see also Fig. 5). The width of the links is proportional to the amount of biomass flow. It exemplifies the problem of analysing the topology of food-webs without taking link magnitude into account.

This pattern is revealed by the degree distribution of a network, which plots the cumulative frequency distribution of nodes with a given number of links (number of nodes with 1, 2, 3... links). A power law distribution demonstrates a scale-free structure (see Chapter 1). Melian and Bascompte (2002) (183) have compared different networks (protein, random and food-web networks) and analyzed yet another aspect of their structure: they concentrated on average connectivity of neighbours in a network. To achieve this, first all nodes with one link are considered, and the average number of links of their single neighbour is computed; then, this process is repeated for nodes with $2,3,4 \ldots$ links, and the mean 
number of links of the neighbours is plotted on a log-log scale, with the average connectivity as ordinate and number of links as abscissa. It revealed that food-webs have a very different structure than random and protein networks. In protein networks, nodes with many links tend to be connected to nodes with very few links; this is not the case for food-webs where the reverse happens. This gives rise to groups of species that form highly connected subwebs (Fig. 15), a pattern explored in Melian and Bascompte (2004) (184). In another intriguing study, Williams et al. (2002) (185) have studied the minimum number of links necessary to go from any one species to any other in a food-web. This is a very important feature to understand how a perturbation in a network (e.g. the extinction of a species) may propagate to the rest of the network. They found that food-webs possess the so-called "small-world" property, that is, the

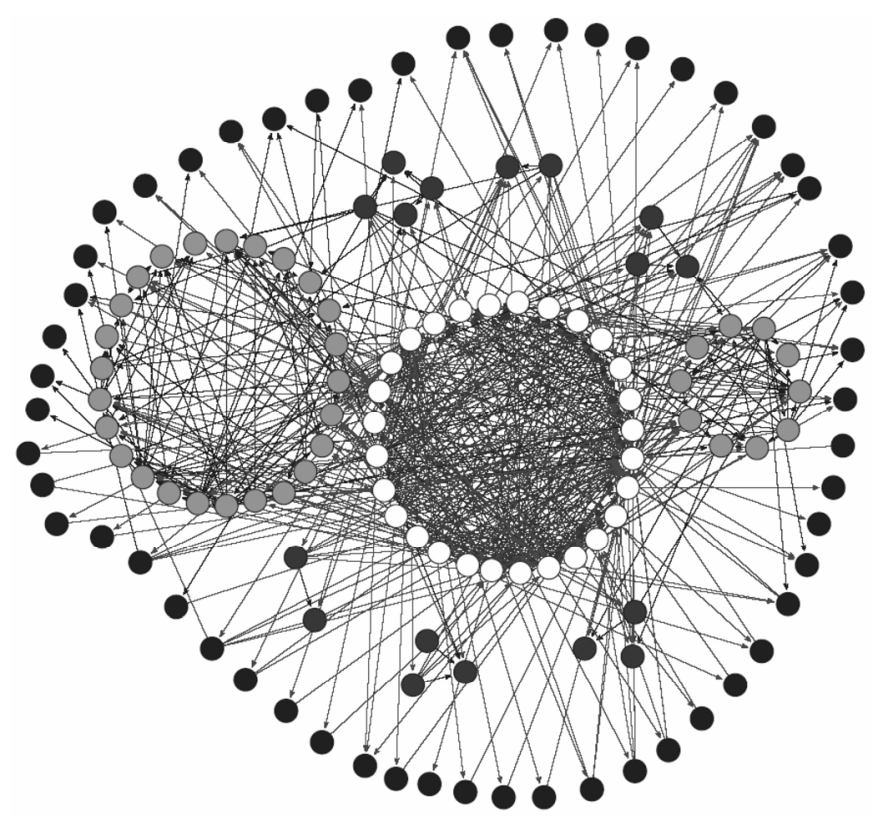

Figure 15. A representation of the food-web of Ythan estuary (data from Hall and Raffaelli 1991) (184) where dense subsets of trophically interacting species are emphasized (from Melián and Bascompte 2004) (184). Typically, food-webs are organized around few subwebs of highly interacting species. (Reprinted from Melián and Bascompte, 2004, with permission of the Ecological Society of America.) 
characteristic path length - the mean distance between all nodes - is typically very short (between 1.4 and 2.7 for the dataset studied). These are examples of important patterns revealed by applying network analysis tools. It shows that food-webs have highly cohesive structure, with typically one or few large and highly trophically interconnected subwebs, and with the vast majority of species not more distant than three links apart of each other. The quest for patterns in food-web structure continues to attract ecologists and theoreticians, with explorations on universal scaling in networks $(186 a, 186 b, 187,188)$.

This quest for regularities in food-web structure is a basic step in the process of developing models of food-web structure. If indeed such general patterns are valid, they represent the fundamental patterns in real ecosystems that must be incorporated into models, as basic constraints and as standards for testing hypothesized processes underlying food-web structure. Models have been formulated to answer this question (141,189-193)(see Chapter 12). The so-called niche-hierarchy model of Sugihara $(194,189)$ has been discussed above. It is important to be aware that it focuses on niche-overlap graphs, but not directly on food-web graphs.

So, while it constrains the possible configurations of food-webs, it does not actually provide a recipe to build a food-web matrix. Cohen and Newman (1985) (141) were the first to suggest a model that reproduces the topology of trophic interactions in a community, the cascade model. Two parameters are needed, the number of species and the number of trophic interactions - a shared characteristic of this kind of static models of food-web structure. The cascade model is stochastic and based on a very simple rule: all species are ranked according to a single hierarchy, and species can only consume prey of lower rank, with a probability similar for all species and equal to twice the connectance (i.e. $2 \cdot \mathrm{L} / \mathrm{S}^{2}$ ). This gives rise to matrices that are triangulated, where cannibalistic as well as longer loops (e.g. A eats B and B eats A) are forbidden (Fig. 16b). As said above, the single niche dimension in this model was interpreted to represent a body size hierarchy: consumers must usually be larger than their prey to be able to consume them (140). This very simple constraint appears to have non trivial consequences for the topology of food-webs. Interestingly, the idea of a single hierarchy came from the 
observation that many real food-webs from early datasets were interval. However, Cohen and Palka (1990) (195) later discovered that the cascade model produces an excess of non-triangulated webs compared to observed food-webs, at least for webs with more than 16 species. They concluded that most reported webs with a small number of species were incomplete representation of real communities, and that consequently more than one dimension was necessary to describe trophic niches of communities. A later study explored quantitatively the level to which food-webs departed from intervality by counting the number of chordless circuits with four consumers (see Fig. 12) in niche-overlap graphs (196). It was found that the cascade model generates a large surplus of such circuits compared to the niche-overlap graph of Ythan estuary (197). Williams and Martinez (2000) (190) confirmed that the cascade model poorly reproduces the structure of highly resolved food-webs. However, the importance of body size for food-web structure has been confirmed (167), and fostered the development of a new analytical representation of food-web structure where abundance, body size, and trophic information are combined $(198,199)$. The partial failure of the cascade model to reproduce real patterns led Williams and Martinez (2000) (190) to formulate the niche model (Fig. 16c), which is based on the assumption of a single trophic niche dimension where consumers eat all prey within a range. This produces contiguous diets for all species; that is, it assumes that it is possible to arrange all prey species so that no gap is present in any of the diet of the consumers (see Fig. 16c, and note that all columns have continuous range of ones). Note that this model generates nothing but interval food-webs. It is intriguing since it is able to reproduce closely many patterns seen in food-web structure, and represents a major improvement over the cascade model. The niche model however suffers from a serious drawback: the assumption of continuous diets is never observed in recent highly resolved food-webs (191). That is, it is not possible to order the prey species and remove all gaps in the diets of consumers. This is another hint that more than one dimension are needed to represent the trophic structure of real communities. Cattin et al. (2004) (191) used an evolutionary approach to generate food-web matrices: they postulated that diets of species could be understood as resulting from phylogenetic constraints and adaptation (see also ref. 200). A consumer's 


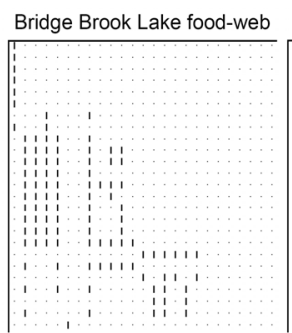

a

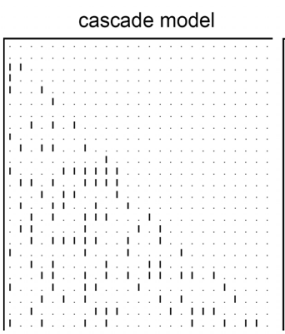

b

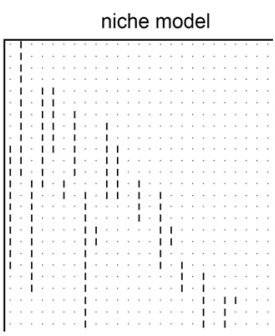

c nested-hierarchy model

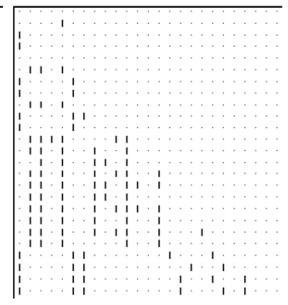

d

Figure 16. (a) Food-web matrix of Bridge Brook Lake (data from Havens 1992) (152), and one realization of stochastic models of food-web structure with similar numbers of species and links: (b) the cascade model (152), (c) the niche model (190), and (d) the nested-hierarchy model (191). Columns are species in their role of consumers, and rows are species in their role of prey; a "I" indicates a trophic interaction.

diet is constrained by its phylogenetic origin: taxonomically related species share similar ancestral morphological features that influence the kind of species they can prey on. For example, all warblers of the Phylloscopus genus possess a beak suited to prey on insects. This connection between phylogenetic origin and diet was substantiated with statistical analyses relating matrices of trophic and taxonomic similarity. However, phylogenetic constraints are not sufficient to explain trophic structure since species have to adapt to varying environments in order to survive, diverging from close relatives in their behaviour, and possibly innovating by using new food sources. Cattin et al. (2004) (191) proposed simple rules that incorporated these evolutionary processes, and found that food-webs generated in this way were very close to observed ones, with the advantage of correctly accounting for the level of chordless circuits found in real communities when compared to the niche model. The prime difference between former models and the nestedhierarchy model is that the process of generating food-webs is sequential in the latter: consumers are added one by one in the community, and their diet depends on existing ones. This feature is meant to represent a process where new species are not free to consume any kind of prey if they are taxonomically related to already present species. Other models of food-web structure based on evolutionary dynamics have been devised $(192,193)$, and their ability to closely reproduce observed trophic 
structures is impressive. This success of evolutionary models witnesses a change in ecological thinking about communities. Earlier studies have mainly focused on ecological processes like competition and niche theory, predation, or trophodynamics, to explain community patterns (e.g. refs. 201-206). Community ecologists have become more and more aware of the importance of historical effects, and notably on "deep history" - in other words, phylogeny - on community structure (e.g. refs. 4,207-212).

Finally, another fundamental question is to understand the effect of food-web topology on community dynamics. This research is very important to understand community responses to extinctions of species that may be driven by climate changes. Interestingly, it has been tackled by purely static analyses of network topology, as well as by more traditional dynamical models. The former approach explores the possibility of secondary extinctions, that is of possible cascading effects after the removal of species (213-215). In this vein, Alessina and Bodini (2004) (216) have developed the use of so-called dominator trees to visualize species that are bottlenecks for the flow of biomass within the community. This issue on food-web dynamics is tackled in more details in Chapter 12.

\section{Indirect effects}

A very important aspect in the study of ecological networks is the concept of indirect effects, that is, effects between two species that are not directly interacting, and which are mediated by other interacting species in the network. Such indirect effects can have profound influence on community dynamics. This aspect is typically overlooked in many studies on populations and, especially for conservation issues, the omission of important third-party players in the system studied can lead to inappropriate management recommendations (217-219). Other examples come from the evolutionary biology of plant-herbivore interactions, which are typically studied without regard to other interacting species. When considered in a community context, the outcome of such interactions yield results that often are not accounted for by classical theories (220-221). Though indirect effects can in principle 
occur between any species in a food-web (222), they are most often considered between adjacent species, which allows a classification of basic forms: trophic cascade, apparent competition, keystone predation, and consumptive competition (Fig. 17). The latter is the most straightforward and lies at the basis of niche-overlap graphs (Fig. 12, 13). The term trophic cascade was coined by Robert Paine (1980) (122), but the idea of top-down effects propagating through food-chains was already explicit in Camerano (1880) (17), and was at the core of theories of community organization by Hairston et al. (1960) (223) and Fretwell (1977) (224). A fascinating study by Carpenter and co-workers $(225,226)$ showed how the fourth trophic level can affect the first one in a lake ecosystem: large fishes are able to suppress many small fishes, in turn unleashing herbivores and eventually decreasing strongly the biomass of plants. A removal of the large predatory fishes produces a massive bloom of primary producers. Trophic cascades have been under deep scrutiny by ecologists, with questions about their importance in aquatic versus terrestrial systems (227-230), about the processes triggering their occurrence (231-134), or about their dynamics $(235,176,236)$. Indirect mutualism is another form of indirect effect that was discussed above (Fig. 6). Keystone predation is yet another kind of indirect effect: by preying upon a superior competitor, a consumer can enhance the abundance of an inferior competitor. The existence of configurations leading to apparent competition was first described by Holt (1977) (237): the increase in abundance of a prey may increase the abundance of its predator; if this predator is shared by another prey, which does not compete with the first one, then the abundance of this prey may decrease, giving rise to the appearance of competition between both prey (Holt and Lawton 1994) (238). It is worth noting that Sugihara's (1982) (194) resource graphs (Fig. 13) provides a representation of possible apparent competition between prey in a community. By giving a complete picture of biomass flows, food-webs by essence incorporate all informations needed to appreciate the importance of indirect effects in a community. However, it took a rather long time to ecologists to appreciate the dynamical importance of such effects - for example, indirect effects are not treated in the community ecology textbook of Putman (239), while a whole chapter is devoted to this subject in Morin (3). 


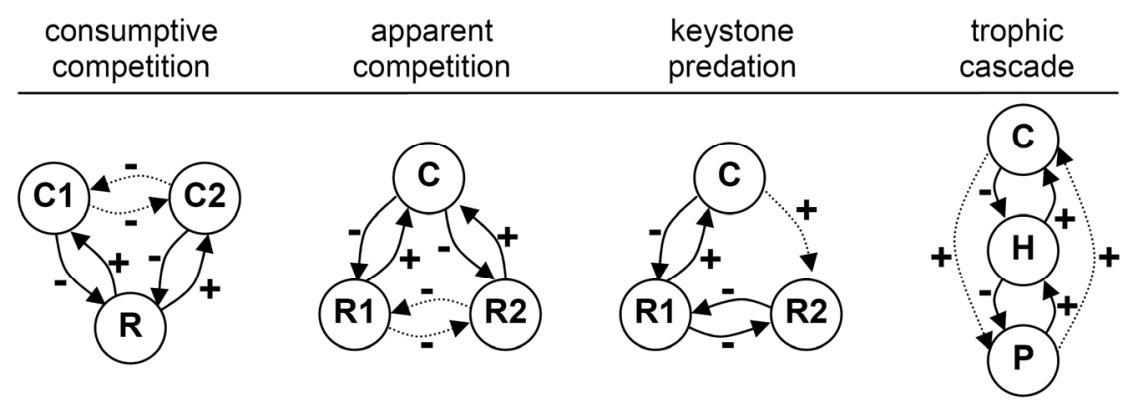

Figure 17. Typical forms of indirect interactions. Solid lines are direct interactions and dotted lines are the resulting indirect interaction.

In the context of network analyses, the various kinds of indirect effects have been considered as modules or building blocks of food-webs (240) - with the addition of configurations like intraguild predation, a case where an omnivorous predator and its prey both share the same resource (241,242). For example, Bascompte et al. (2005) (243) have extracted from a large and highly resolved food-web all modules of two types: simple food-chains and intraguild predation. They analyzed how interaction strength was distributed within these modules. In a simple food-chain module with three species and two links, this entails looking at the co-occurrence of strong interactions. They found that two cooccurring strong links were rare and that, when present, they were "shortcut" by a strong omnivory link more often than expected by chance - that is, they formed an intraguild predation module. In all, such patterns have a strong stabilizing effect on community dynamics.

One of the most successful research programs on indirect effects is the work of Charles Godfray and co-workers on apparent competition in ecological networks. They studied mostly herbivores-parasitoid systems (parasitoids have a mode of life intermediate between predation and parasitism: they typically lay their egg inside a host and the larvae will develop by feeding within the live body; most parasitoids are wasps). The beauty of this system is that it is possible to accurately estimate the magnitude of the interactions by collecting hosts and counting the number of parasitoid larvae; it is also possible to take into account secondary parasitoids, which lay their eggs inside the parasitoid larvae or 
mummy when they are still in their herbivore host. In this way, it is possible to document very precisely the trophic interactions within such systems (244-250). Once quantitative food-webs are available, it is possible to produce quantitative resource graphs (called in this case parasitoid overlap graphs) where herbivores are linked if they share a parasitoid. The interest of obtaining such weighted graphs is that it is then possible to isolate pairs of herbivores that are likely to be affected by strong apparent competition. Such pairs were subjected to experimental manipulation and the significance of indirect effects was assessed in this way $(251,247,252)$.

\section{Networking with non-trophic interactions}

As said in the introduction, networks of species linked by different kind of interactions are quite uncommon compared to the wealth of food-web studies, and up to now, I have considered almost exclusively networks of species linked by trophic interactions. From food-webs, it is possible to generate graphs of species linked by consumptive competition. Such niche-overlap graphs have been discussed above. When considering competition without information from food-webs, ecologists have typically assessed the magnitude of interactions indirectly through measures of body size, morphology, and micro-habitat use (e.g. refs. $253,254)$, with the assumption that they are sufficient to account for most mechanisms leading to competition (e.g. consumption of shared resources, or preemption of space). From such information, it is possible to compute a squared quantitative matrix of niche similarity. Pairs of species overlapping extensively in their niche use are expected to be strong competitors. There are to my knowledge few studies where such competition matrices were used to generate networks. The preferred analytical tool is cluster analysis, which provides a hierarchical structure of community organization. An exception is Sugihara's (1982) (194) analysis of a dataset of 11 bird communities from Cody (1974) (201). He built the niche overlap graphs of such communities at various thresholds of interaction magnitude, and found that the absence of chordless cycles (see Fig. 12) was a robust feature of communities whatever the level of competition used to construct such graphs. 
Mutualistic interactions between plants and their pollinators have typically been thought to be quite specialized. However, recent studies have showed that it is often not the case: many plants have numerous pollinators and many pollinators visit different plant species. This discovery comes from the analysis of mutualistic networks of plantspollinators and plants-seed dispersers (255-257). It is important in many respects. First, it shows that, when viewed at a community level, coevolution between pollinators and plants is not "multi-channel" like, between tightly co-adapted pairs, but diffuse over the whole network. Second, this knowledge is crucial when assessing the possible dispersion of pollens of genetically modified plants, and is also very important for conservation issues (258). Finally, it is very important for community dynamics. Bascompte et al. (2003) (259) and Jordano et al. (2003) (260) have analyzed precisely the structure of plant-animal networks in a large dataset comprising more than 50 networks. The former study found that such networks are organized in a highly nested way: specialist species interact only with subsets of species that are interacting with many generalists. This pattern generates highly asymmetrical structures, with the community organized in a cohesive manner around a central core of interacting species. The latter study explored scaling relationships in this dataset. They found that, contrary to other studied networks, the degree distribution (the cumulative frequency distribution of numbers of species with a given number of links) was not scale-free, that is, it did not decay as a power law. They hypothesized that the construction of such networks followed a process where morphological and phenological constraints restricted the number of possible links between species, thus generating networks with a strong core of interacting species and a wealth of satellite species attached loosely to this core, a pattern that may confer a high dynamical robustness to these systems.

Finally, to my knowledge very few studies at the community level have incorporated different kinds of interactions in a similar network. One such work is the recent contribution of Melian, Bascompte and Jordano (in Melián 2005) (12), who tackled the analysis of a network comprising plants, herbivores, pollinators, and seed-dispersers (a total of 394 species). They analyzed degree distributions and subwebs (see above), and found interestingly that plant species that were involved in 
the core of interactions with pollinators were at the same time exposed heavily to herbivores. Looking only at mutualistic interactions may give the impression that this core of interacting species does form a barrier against the propagation of disturbances in this system. Incorporating herbivores evidences the fact that these species are also more prone to be destabilized by herbivores. In all, both effects may cancel out. This shows that one must be careful when drawing conclusions about community dynamics from studies of only one kind of interactions. This highlights the need of a multi-interactive perspective of ecological networks.

\section{Future avenues of research}

I hope that the present chapter has given to the reader a palette of possibilities to study ecological networks. I believe that apprehending natural communities as ecological networks has a strong potential to become a paradigmatic approach in ecology. Firstly because analytical tools are becoming more and more available, but more importantly because ecological networks provide a framework to link various schools in ecology and evolution that have largely progressed independently. For example, evolutionary theories about plant-herbivores or host-parasites can be scaled-up, and energetic based theories of ecosystem structure can be scaled-down at the same network level. Such an undertaking is paved with theoretical and empirical challenges. To be successful, I believe that developments are particularly needed in the following domains. First, it is desirable to tackle ecological networks in a multi-interactive manner, that is, to integrate all kinds of interactions. Trophic interactions are of course paramount to understand the dynamics of communities, but other kind of links are as crucial, some of which are overlooked in ecological networks - for example facilitation (2615), ecosystem engineering (262264), without forgetting ecological stoichiometry - the balance of different chemicals in ecological interactions (265). Models and theories of community structure and functioning need to prove useful in their predictions, for example when effects of climatic forcing or of other perturbations are considered. I believe that this goal can be fully achieved only by integrating all kinds of interactions in the same 
framework. Second, interactions should be not only reported as present of absent, but also quantified in appropriate units, and abundance of species should also be estimated. Weighted networks provide much more sensible information on community structure, and suffer less from effects due to different levels of sampling effort exerted in documenting communities (266). Third, such an undertaking will be successful only with high-quality datasets, which requires a strong involvement of field ecologists and taxonomists. Here, a difficult methodological aspect is the quantitative documentation of interactions. Trophic interactions are notably difficult to quantify from observations, and molecular methods may be helpful in this task (e.g. ref. 267). Finally, communities must be studied at various temporal and spatial scales (268-270). The recent concepts of metacommunities (271) and meta-ecosystems (5) emphasizes dispersal and allochthonous inputs as key processes for community structure. They are totally relevant in this respect, which views communities as networks of networks.

In all, these issues are a plea for a multidisciplinary approach to the ecology of natural communities. This should prevent theoreticians to forget that nodes in a network are not just abstract objects but species, and population ecologists that species interact not only with their prey or parasites, but within a larger constellation of interacting species. Ecological networks make connections between species in a community; they should also foster ecologists and evolutionists of diverse disciplines, as well as mathematicians and physicists, to make connections in a fruitful network.

\section{Acknowledgements}

I am grateful to all colleagues and friends who helped me to sharpen my ideas about community ecology, to all field ecologists involved in data collection presented here, and to Russell Naisbit for revising the text. My apologies to all whose contributions could not be tackled in the Chapter. This research was supported by a Swiss NSF grant (3100A0-113843). 


\section{References}

1. Haeckel, E. (1866) Generelle Morphologie der Organismen, 2 Vols. Georg Reimer Verlag, Berlin.

2. Fauth, J.E., Bernardo, J., Camara, M., Reserarits, W.J.J., Van Buskirk, J. and McCollum, S.A. (1996) Simplifying the jargon of community ecology: a conceptual approach. American Naturalist, 147, 282-286.

3. Morin, P. (1999) Community Ecology. Blackwell Science.

4. Drake, J.A. (1990) Communities as assembled structures: do rules govern pattern? Trends in Ecology and Evolution, 5, 159-164.

5. Loreau, M. and Mouquet, N. (1999) Immigration and the maintenance of local species diversity. American Naturalist, 154, 427-440.

6. Root, R. (1967) The niche exploitation pattern of the blue-gray gnatcatcher. Ecological Monographs, 37, 317-350

7. Hubbell, S.P. (2001) The Unified Neutral Theory of Biodiversity and Biogeography. Princeton University Press, Princeton, Oxford.

8. Volkov, I., Banavar, J.R., Hubbell, S.P. and Maritan, A. (2003) Neutral theory and relative species abundance in ecology. Nature, 424, 1035-1037.

9. Sugihara, G., Bersier, L.F., Southwood, T.R.E., Pimm, S.L. and May, R.M. (2003) Predicted correspondence between species abundances and dendrograms of niche similarities. Proceedings of the National Academy of Sciences of the United States of America, 100, 5246-5251.

10. Yodzis, P. (1989) Introduction to Theoretical Ecology. Harper and Row, NewYork.

11. Ricklefs, R.E. and Miller, G.L. (1999) Ecology. W.H. Freeman and Company, New York.

12. Melián, C.J. (2005) On the Structure and Dynamics of Ecological Networks. PhD thesis, Universidad de Alcalá, Spain.

13. Darwin, C. (1859) On the Origin of Species by Means of Natural Selection, or the Preservation of Favoured Races in the Struggle for Life. 1st edition John Murray, London.

14. Hagen, J. (1992). An entangled bank: The origins of ecosystems ecology. Rutgers Univ. Press, New Brunswick.

15. Golley, F.B. (1993) A history of the ecosystem concept in ecology: More than the sum of the parts. Yale Univ. Press, New Haven.

16. Kingsland, S.E. (1995) Modeling nature : episodes in the history of population ecology. University of Chicago Press, Chicago.

17. Camerano, L. (1880) Dell'equilibrio dei viventi merce la reciproca distruzione. Atti della Reale Accademia delle Scienze di Torino, 15, 393-414. (For an English translation by Claudia M. Jacobi: Levin, S.A., ed. (1994) Frontiers in Mathematical Biology. Springer Verlag, Berlin, 360-380.

18. Darwin, C. (1839) Journal of Researches into the Geology and Natural History of the Various Countries Visited by H.M.S. Beagle, Under the Command of Captain Fitzroy, R.N. from 1832 to 1836 . Henry Colburn, London. Reprinted: Culture et Civilisation, Brussels, 1969. 
19. Cohen, J.E. (1994) Lorenzo Camerano's contribution to early food web theory. In Frontiers in Mathematical Biology (Levin, S.A.),. 351-359. Springer Verlag, Berlin.

20. Möbius, K. (1877) Die Auster und die Austernwirtschaft. Wiegand, Hempel and Parey, Berlin.

21. Forbes, E. (1843) Report on the Mollusca and Radiata of the Aegean sea, and on their distribution, considered as bearing on geology. Report of the 13th meeting of the British Association for the Advancement of Science held at Cork. 130-93.

22. Ehrlich, P.R. and Birch, L.C. (1967) The "balance of nature" and "population control". American Naturalist, 101, 97-107.

23. Slobodkin, L.B., Smith, F.E. and Hairston, N.G. (1967) Regulation in terrestrial ecosystems, and the implied balance of nature. American Naturalist, 101, 109-124.

24. Pimm, S.L. (1991) The Balance of Nature? Ecological Issues in the Conservation of Species and Communities. The University of Chicago Press, Chicago.

25. McCann, K.S. (2000) The diversity-stability debate. Nature, 405, 228-233.

26. May, R.M. (1974) Stability and complexity of model ecosystems. 2nd ed. Princeton University Press, Princeton.

27. Estes, J.A., Tinker, M. T., Williams, T. M., and Doak, D. F. (1998) Killer whale predation on sea otters linking oceanic and nearshore ecosystems. Science, 282, 473-476.

28. Brett, M.T. and Goldman, C.R. (1997) Consumer versus resource control in freshwater pelagic food webs. Science, 275, 384.

29. Carpenter, S.R., Kitchell, J.F. and Hodgson, J.F. (1985) Cascading trophic interactions and lake productivity. BioScience, 35, 634-639.

30. Cohen, J.E. and Briand, F. (1984) Trophic links of community food web. Proceedings of the National Academy of Sciences of the United States of America, 81, 4105-4109.

31. Scheffer, M. (1999) Searching explanations of nature in the mirror world of math. Conservation Ecology, 3(2) art. 11.

32. Allee, W.C., Emerson, A.E., Park, O., Park, T., and Schmidt, K.P. (1949) Principles of animal ecology. Saunders, Philadelphia.

33. Oksanen, L. (1991) A century of community ecology: how much progress? Trends in Ecology and Evolution, 6, 294-296.

34. Pierce, W.D., Cushman, R A. and Hood, C.E. (1912) The insect enemies of the cotton boll weevil. U.S. Department of Agriculture Bureau of Entomology Bulletin 100, 99.

35. Shelford, V.E. (1913) Animal Communities in Temperate America as Illustrated in the Chicago Region. The Geographic Society of Chicago Bulletin No. 5.

36. Summerhayes, V.S. and Elton, C.S. (1923) Contributions to the ecology of Spitsbergen and Bear Island. Journal of Ecology, 11, 214-286.

37. Elton, C.S. (1927) Animal ecology. Sidgwick and Jackson, London.

38. Polis, G.A. and Hurd, S.D. (1996) Linking marine and terrestrial food webs: Allochthonous input from the ocean supports high secondary productivity on small islands and coastal land communities. American Naturalist, 147, 396-423. 
39. Huxel, G.R., McCann, K. and Polis, G.A. (2002) Effects of partitioning allochthonous and autochthonous resources on food web stability. Ecological Research, 17, 419-432.

40. Stapp, P. and Polis, G.A. (2003) Marine resources subsidize insular rodent populations in the Gulf of California, Mexico. Oecologia, 134, 496-504.

41. Cuddington, K. (2001) The "Balance of Nature" metaphor and equilibrium in population ecology. Biology and Philosophy, 16, 463-479.

42. Clements, F.E. (1916) Plant succession, an analysis of the development of vegetation. Carnegie Institution of Washington, Publications 242, 1-512.

43. Gleason, H.A. (1926) The individualistic concept of the plant association. Bulletin of the Torrey Botanical Club, 53, 7-26.

44. Elton, C.S. (1930) Animal Ecology and Evolution. Oxford University Press, NewYork.

45. Elton, C.S. (1958) The Ecology of Invasion by Animals and Plants. Methuen, London.

46. Richards, O.W. (1926) Studies on the ecology of English heaths. III. Animal communities of the felling and burn successions at Oxshott Heath, Surrey. Journal of Ecology, 14, 244-281.

47. Bird, R.D. (1930) Biotic communities of the aspen parkland of central Canada. Ecology, 11, 356-442.

48. Lindeman, R.L. (1942) The trophic-dynamic aspect of ecology. Ecology, 23, 399417.

49. Baird, D. and Ulanowicz, R.E. (1989) The seasonal dynamics of the Chesapeake Bay ecosystem. Ecological Monographs, 59, 329-364.

50. Ulanowicz, R.E. (1995) Ecosystem trophic foundations: Lindeman exonerata. In Complex Ecology: The Part-Whole Relation in Ecosystems (Patten, B.C. and Jørgensen, S.E.). 549-560. Prentice Hall PTR, Engelwood Cliffs, NJ.

51. Odum, E.P. (1953) Fundamentals of Ecology. Saunders, Philadelphia.

52. Odum, E.P. (1969) The strategy of ecosystem development. Science, 164, 262270.

53. Odum, H.T. (1988) Self-organization, transformity, and information. Science, 242, 1132-1139.

54. Patten, B. C. (1995) Network integration of ecological extremal principles: exergy, emergy, power, ascendancy, and indirect effects. Ecological Modelling 79, 75-84.

55. Hau, J.L. and Bakshi B. R. (2004) Promise and problems of emergy analysis. Ecological Modelling 178, 215-225.

56. Brown, M.T. and Ulgiati, S. (2004) Energy quality, emergy, and transformity: H.T. Odum's contributions to quantifying and understanding systems. Ecological Modelling, 178, :201-213.

57. Ulanowicz, R.E. (1997) Ecology, the Ascendent Perspective. Complexity in Ecological Systems Series. Columbia University Press, New York.

58. Wynne-Edwards, V.C. (1962) Animal Dispersion in Relation to Social Behaviour. Hafner Publishing, New York.

59. Wilson, D.S. (2001) Evolutionary biology: Struggling to escape exclusively individual selection. Quarterly Review of Biology, 76, 199-205. 
60. Lewontin, R.C. (1970) The units of selection. Annual Review of Ecology and Systematics, 1, 1-18.

61. Maynard Smith, J. (1976) Group selection. Quarterly Review of Biology, 51, 277283.

62. Wilson, D.S. (1997) Introduction: Multilevel selection theory comes of age. American Naturalist, 150, S1-S4.

63. Keller, L. (ed.) (1999) Levels of Selection in Evolution. Princeton University Press, Princeton, New Jersey.

64. Swenson, W., Wilson, D.S. and Elias, R. (2000) Artificial ecosystem selection. Proceedings of the National Academy of Sciences of the USA, 97, 9110-9114.

65. Odling-Smee, F.J., Laland, K.N. and Feldman M.W. (2003) Niche Construction: The Neglected Process in Evolution. Princeton University Press, Princeton, New Jersey.

66. Patten, B.C. (ed.) (1975) System Analysis and Simulation in Ecology. Academic Press, New York.

67. Fath, and Patten, B.C. (1999) Review of the foundations of network environ analysis. Ecosystems, 2, 167-179.

68. Patten B.C. and Jørgensen, S.E. (eds) (1995) Complex Ecology: The Part-Whole Relation in Ecosystems. Prentice Hall PTR, Engelwood Cliffs, NJ.

69. Ulanowicz, R.E. (1986) Growth and Development: Ecosystems Phenomenology. Springer Verlag,

70. Ulanowicz, R.E. and Wolff, W.F. (1991) Ecosystem flow networks: Loaded dice? Mathematical Biosciences, 103, 45-68.

71. Warren, P.H. (1994) Making connections in food webs. Trends in Ecology and Evolution, 9,136-141.

72. Martinez, N.D. (1992) Constant connectance in community food webs. American Naturalist, 139, 1208-1218.

73. Ulanowicz, R.E. (2002) The balance between adaptability and adaptation. BioSystems, 64, 13-22.

74. Paine, R.T. (1966) Food web complexity and species diversity. American Naturalist, 100, 65-75.

75. MacArthur, R.H. (1955) Fluctuations of animal populations, and a measure of community stability. Ecology, 36, 533-536.

76. Begon, M., Harper, J.L. and Townsend, C.R. (1996) Ecology. Individuals, Populations and Communities. 3rd edition. Blackwell Science, Malden, MA, USA.

77. Magurran, A.E. (2004) Measuring Biological Diversity. Blackwell Science, Malden, MA.

78. Niering, W.A. (1963) Terrestrial ecology of Kapingamarangi Atoll, Caroline Islands. Ecological Monographs, 33, 131-160.

79. Clarke, T.A., Flechsig, A.O. and Grigg, R.W. (1967) Ecological studies during Project Sealab II. Science, 157, 1381-1389.

80. Bersier, L.F., Dixon, P. and Sugihara, G. (1999) Scale-invariant or scale-dependent behavior of the link density property in food webs: A matter of sampling effort? American Naturalist, 153, 676-682. 
81. May, R.M. (1972) Will a large complex system be stable? Nature, 238, 413-414.

82. May, R.M. (2001) Stability and complexity of model ecosystems. 2nd ed with a new introduction. Princeton University Press, Princeton.

83. Hastings, H. (1982) The May-Wigner stability theorem. Journal of Theoretical Biology, 97, 155-166.

84. Polis, G.A. (1994) Food webs, trophic cascades and community structure. Australian Journal of Ecology, 19, 121-136.

85. Cohen, J.E. and Newman, C.M. (1984) The stability of large random matrices and their products. Annals of Probability, 12, 283-310.

86. Sinha, S. and Sinha, S. (2005) Evidence of universality for the May-Wigner stability theorem for random networks with local dynamics. Physical Review E, 71, $0209021-4$.

87. Tilman, D. and Downing, J.A. (1994) Biodiversity and stability in grasslands. Nature, 367, 363-365.

88. Tilman, D. (1996) Biodiversity: population versus ecosystem stability. Ecology, 77, 350-363.

89. Tilman, D. (1999) The ecological consequences of changes in biodiversity: A search for general principles. Ecology, 80, 1455-1474.

90. Tilman, D., Wedin, D. and Knops, J. (1996) Productivity and sustainability influenced by biodiversity in grassland ecosystems. Nature, 379, 718-720.

91. Hector, A., Schmid, B., Beierkuhnlein, C., Caldeira, M.C., Diemer, M., Dimitrakopoulos, P.G., Finn, J.A., Freitas, H., Giller, P.S., Good, J., Harris, R., Högberg, P., Huss-Danell, K., Joshi, J., Jumpponen, A., Körner, C., Leadley, P.W., Loreau, M., Minns, A., Mulder, C.P.H., O'Donovan, G., Otway, S.J., Pereira, J.S., Prinz, A., Read, D.J., Scherer-Lorenzen, M., Schulze, E.-D., Siamantziouras, A.-S.D., Spehn, E.M., Terry, A.C., Troumbis, A.Y., Woodward, F.I., Yachi, S. and Lawton J. H. (1999) Plant diversity and productivity experiments in european grasslands. Science, 286, 1123-1127.

92. Naeem, S., Thompson, L.J., Lawlor, S.P., Lawton, J.H., and Woodfin, R.M. (1994) Declining biodiversity can alter the performance of ecosystems. Nature, 368, 734737.

93. Doak, D.F., Bigger, D., Harding, E.K., Marvier, M.A., O'Malley, R.E. and Thomson, D. (1998) The statistical inevitability of stability-diversity relationships in community ecology. American Naturalist, 151, 264-276.

94. Tilman, D., Lehman, C.L. and Bristow, C.E. (1998) Diversity-stability relationships: statistical inevitability or ecological consequence. American Naturalist, 151, 277-282.

95. Loreau, M. and Hector, A. (2001) Partitioning selection and complementarity in biodiversity experiments. Nature, 412, 72-76.

96. Loreau, M., Naeem, S., Inchausti, P., Bengtsson, J., Grime, J.P., Hector, A., Hooper, D.U., Huston, M.A., Raffaelli, D., Schmid, B., Tilman, D. and Wardle, D.A. (2001) Biodiversity and ecosystem functioning: Current knowledge and future challenges. Science, 294, 804-808.

97. Loreau, M., Naeem, S., Inchausti, P. (eds) (2002) Biodiversity and Ecosystem Functioning Synthesis and Perspectives. Oxford University Press, Oxford, UK. 
98. McGrady-Steed, J. and Morin, P.J. (2000) Biodiversity, density compensation, and the dynamics of populations and functional groups. Ecology, 81, 361-373.

99. Paine, R.T. (2002) Trophic control of production in a rocky intertidal community. Science, 296, 736-739.

100. Thébault, E. and Loreau, M. (2003) Food-web constraints on biodiversityecosystem functioning relationships. Proceedings of the National Academy of Sciences of the USA, 100, 14949-14954.

101. Fagan, W. F. (1997) Omnivory as a stabilizing feature of natural communities. American Naturalist, 150, 554-567.

102. Pimm, S. L. and Lawton, J. H. (1978) On feeding on more than one trophic level. Nature, 275, 542-544.

103. Pimm, S. L. (1982) Food webs. Chapman and Hall, New York.

104. Pimm, S. L., Lawton, J. H. and Cohen, J. E. (1991) Food web patterns and their consequences. Nature, 350, 669-674.

105. Holyoak, M. and Sachdev, S. (1999) Omnivory and the stability of simple food webs. Oecologia, 117, 413-419.

106. Morin, P. (1999b) Productivity, intraguild predation, and population dynamics in experimental food webs. Ecology, 80, 752-760.

107. Holling, C.S. (1966) The functional response of invertebrate predators to prey density. Memoirs of the Entomological Society of Canada, 48, 1-60.

108. Arditi, R. and Ginzburg, L.R. (1989) Coupling in predator-prey dynamics: ratio dependence. Journal of Theoretical Biology, 139, 311-326.

109. Berryman, A.A. (1992) The origins and evolution of predator-prey theory. Ecology, 73, 1530-1535.

110. Abrams, P.A. (1994) The fallacies of "ratio-dependent" predation. Ecology, 75, 1842-1850.

111. Abrams, P.A. and Ginzburg, L.R. (2000) The nature of predation: prey dependent, ratio dependent or neither? Trends in Ecology and Evolution, 15, 337-341.

112. Schenk, D., Bersier, L.F. and Bacher, S. (2005) An experimental test of the nature of predation: neither prey- nor ratio-dependent. Journal of Animal Ecology, 74, 8691.

113. Yodzis, P. (1981) The stability of real ecosystems. Nature 289, 674-676.

114. McCann, K.S, Hastings, A. and Huxel, G.R. (1998) Weak trophic interactions and the balance of nature. Nature 395, 794-798.

115. Berlow, E. (1999) Strong effects of weak interactions in ecological communities. Nature, 398, 330-334.

116. Neutel, A.M., Heesterbeek, J.A.P. and de Ruiter, P.C. (2002) Stability in real food webs: Weak links in long loops. Science, 296, 1120-1123.

117. Huffaker, C.B. (1958) Experimental studies on predation: dispersion factors and predator-prey oscillations. Hilgardia, 27, 343-383.

118. Hochberg,M.E. and Lawton,J.H. (1990) Spatial heterogeneities in parasitism and population dynamics. Oikos, 59, 9-14.

119. Holt,R.D. and Hassell,M.P. (1993) Environmental heterogeneity and the stability of host parasitoid interactions. Journal of Animal Ecology, 62, 89-100. 
120. Keitt, T.H. (1997) Stability and complexity on a lattice: Coexistence of species in an individual-based food web model. Ecological Modelling, 102, 243-258.

121. Petchey, O.L., Gonzalez, A. and Wilson, H.B. (1997) Effects on population persistence: the interaction between environmental noise colour, intraspecific competition and space. Proceedings of the Royal Society of London Series BBiological Sciences, 264, 1841-1847.

122. Paine, R.T. (1992) Food-web analysis through field measurement of per capita interaction strength. Nature, 355, 73-75.

123. Paine, R.T. (1980) Food webs: linkage, interaction strength and community infrastructure. Journal of Animal Ecology, 49, 667-685.

124. Paine, R.T. (1982) Intertidal food webs: Does connectance describe their essence. In Current Trends in Food Web Theory - Report on a Food Web Workshop (DeAngelis, D.L., Post, W.M. and Sugihara, G.). 11-15. Oak Ridge National Laboratory, Oak Ridge, Tennessee.

125. Paine, R.T. (1988) Food web: road maps of interactions or grist for theoretical development? Ecology, 69, 1648-1654.

126. Raffaelli, D.G. and Hall, S.J. (1996) Assessing the relative importance of trophic links in food webs. In Food Webs: Integration of Patterns and Dynamics (Polis, G.A. and Winemiller, K.O.), 185-191. Chapman and Hall, New York.

127. Wootton, J.T. (1997) Estimates and tests of per capita interaction strength: Diet, abundance, and impact of intertidally foraging birds. Ecological Monographs, 67, 45-64.

128. Laska, M.S. and Wootton, J.T. (1998) Theoretical concepts and empirical approaches to measuring interaction strength. Ecology, 79, 461-476.

129. DeAngelis, D. and Waterhouse, J.C. (1987) Equilibrium and nonequilibrium concepts in ecological models. Ecological Monographs 57, 1-21.

130. Law, R., and Morton, D. (1996) Permanence and the assembly of ecological communities. Ecology 77, 762-775.

131. Huisman, J. and Weissing, F.J. (1999) Biodiversity of plankton by species oscillations and chaos. Nature 402, 407-410.

132. Michalski, J. and Arditi, R. (1995) Food web structure at equilibrium and far from it: Is it the same? Proceedings of the Royal Society of London B Biological Sciences, 259, 217-222.

133. Keitt, T.H. and Marquet, P.A. (1996) The introduced Hawaiian avifauna reconsidered: Evidence for self-organized criticality? Journal of Theoretical Biology, 182, 161-167.

134. Bengtsson, J., Baillie, S.R. and Lawton, J.H. (1997) Community variability increases with time. Oikos, 78, 249-256.

135. Keitt, T.H. and Stanley, H.E. (1998) Dynamics of North American breeding bird populations. Nature, 393, 257-260.

136. Cohen, J.E. (1977) Food webs and the dimensionality of trophic niche space. Proceedings of the National Academy of Sciences of USA, 74, 4533-4536.

137. Cohen, J.E. (1978) Food Webs and Niche Space. Princeton University Press, Princeton, NJ. 
138. Hutchinson, G. (1957) Concluding remarks. Cold Spring Harbor Symposia on Quantitative Biology, 22, 415-427.

139. Leibold, M.A. (1995) The niche concept revisited: Mechanistic models and community context. Ecology, 76, 1371-1382.

140. Lawton, J.H. and Warren, P.H. (1988) Static and dynamic explanations for patterns in food webs. Trends in Ecology and Evolution, 3(9), 242-245.

141. Cohen, J.E. and Newman, C.M. (1985) A stochastic theory of community food webs I. Models and aggregated data. Proceedings of the Royal Society of London B Biological Sciences, 224, 421-448.

142. Cohen, J.E. and Newman, C.M. (1988) Dynamic basis of food web organization. Ecology, 69, 1655-1664.

143. Cohen, J.E., Briand, F. and Newman, C.N. (1990) Community Food Webs: Data and Theory. Springer-Verlag, Berlin.

144. Briand, F. (1983) Environmental Control of Food Web Structure. Ecology, 64, 253-263.

145. Sugihara, G. (1980) Minimal community structure: an explanation of species abundance patterns. American Naturalist, 116, 770-787.

146. Pimm, S.L. (1988) The geometry of niches. Community Ecology. A workshop held at Davis, CA, April 1986 (Hastings, A.), 92-111. Springer-Verlag, Berlin.

147. Briand, F. and Cohen, J.E. (1984) Community food webs have scale-invariant structure. Nature, 307, 264-267.

148. Bersier, L.F., Banašek-Richter, C. and Cattin, M.F. (2002) Quantitative descriptors of food-web matrices. Ecology, 83, 2394-2407.

149. Sugihara, G., Schoenly, K. and Trombla, A. (1989) Scale invariance in food web properties. Science, 245, 48-52.

149a. Rejmánek, M. and Stary, P. (1979) Connectance in real biotic communities and critical values for stability of model ecosystems. Nature, 280, 311-313.

150. May, R.M. (1983) The structure of food webs. Nature (London), 301, 566-568.

151. Bersier, L.F. and Sugihara, G. (1997) Scaling regions for food web properties. Proceedings of the National Academy of Sciences of the United States of America, 94, 1247-1251.

152. Havens, K.E. (1992) Scale and Structure in Natural Food Webs. Science (Washington DC), 257, 1107-1109.

153. Polis, G.A. (1991) Complex trophic interactions in deserts: an empirical critique of food-web theory. American Naturalist, 138, 123-155.

154. Martinez, N.D. (1991) Artifacts or attributes? Effects of resolution on the Little Rock Lake food web. Ecological Monographs, 61, 367-392.

155. Warren, P.H. (1989) Spatial and temporal variation in the structure of a freshwater food web. Oikos, 55, 299-311.

156. Winemiller, K.O. (1990) Spatial and temporal variation in tropical fish trophic networks. Ecological Monographs, 60, 331-367.

157. Hall, S.J. and Raffaelli, D. (1991) Food-web patterns: lessons from a species-rich web. Journal of Animal Ecology, 60, 823-842.

157a. Hall, S.J. and Raffaelli, D.G. (1993) Food webs: theory and reality. Advances in Ecological Research, 24, 187-239. 
158. Goldwasser, L. and Roughgarden, J. (1993) Construction and analysis of a large Caribbean food web. Ecology, 74, 1216-1233.

159. Closs, G.P. and Lake, P.S. (1994) Spatial and temporal variation in the structure of an intermittent-stream food web. Ecological Monographs, 64, 1-21.

160. Deb, D. (1995) Scale-dependence of food web structures: Tropical ponds a paradigm. Oikos, 72, 245-262.

161. Tavares-Cromar, A.F. and Williams, D.D. (1996) The importance of temporal resolution in food web analysis: Evidence for a detritus-based stream . Ecological Monographs, 66, 91-113.

162. Reagan, D.P. and Waide, R.B. (1996) The food web of a tropical rain forest. The University of Chicago Press, Chicago, Illinois, USA.

163. Opitz, S. (1996) Trophic interactions in Caribbean coral reefs. International Centre for Living AquaticResource Management (now WorldFish Center), Penang, Malaysia.

164. Yodzis, P. (1998) Local trophodynamics and the interaction of marine mammals and fisheries in the Benguela ecosystem. Journal of Animal Ecology, 67, 635-658.

165. Almunia, J., Basterretxea, G., Aristegui, J. and Ulanowicz, R.E. (1999) Benthicpelagic switching in a coastal subtropical lagoon. Estuarine Coastal and Shelf Science, 49, 363-384.

166. Martinez, N.D., Hawkins, B.A., Dawah, H.A. and Feifarek, B.P. (1999) Effects of sampling effort on characterization of food-web structure. Ecology, 80, 10441055.

167. Memmott, J., Martinez, N.D. and Cohen, J.E. (2000) Predators, parasitoids and pathogens: Species richness, trophic generality and body sizes in a natural food web. Journal of Animal Ecology, 69, 1-15.

168. Schoener, T.W. (1989) Food webs from the small to the large. Ecology, 70, 15591589.

169. Winemiller, K.O. (1989) Must connectance decrease with species richness. American Naturalist, 134, 960-968.

170. Warren, P.H. (1990) Variation in food-web structure: the determinants of connectance. American Naturalist, 136, 689-700.

171. Martinez, N.D. and Lawton, J.H. (1995) Scale and food-web structure: from local to global. Oikos, 73, 148-154.

172. Deb, D. (1997) Trophic uncertainty vs parsimony in food web research. Oikos, 78, 191-194.

173. Polis, G.A. and Strong, D.R. (1996) Food web complexity and community dynamics. American Naturalist, 147, 813-846.

174. Kitching, R.L. (1987) Spatial and temporal variation in food webs in water-filled treeholes. Oikos, 48, 280-288.

175. Lockwood, J.A., Christiansen, T.A. and LEGG, D.E. (1990) Arthropod preypredator ratios in a sagebrush habitat: Methodological and ecological implications. Ecology, 71, 996-1005.

176. Schoenly, K. and Cohen, J.E. (1991) Temporal variation in food web structure: 16 empirical cases. Ecological Monographs, 61, 267-298. 
177. Schoenly, K.G., Cohen, J.E., Heong, K.L., Arida, G.S., Barrion, A.T. and Litsinger, J.A. (1996) Quantifying the impact of insecticides on food web structure of rice-arthropod populations in a Philippine farmer's irrigated field: A case study. In Food Webs: Integration of Patterns and Dynamics (Polis, G. A. and Winemiller, K. O.). 343-351. Chapman and Hall, New York.

178. Goldwasser, L. and Roughgarden, J. (1997) Sampling effects and the estimation of food-web properties. Ecology, 78, 41-54.

179. Banašek-Richter, C. (2004) Quantitative descriptors and their perspectives for food-web ecology. PhD thesis, Neuchâtel University, Switzerland.

180. Lawton, J.H. (1989) Food webs. In Ecological Concepts (Cherrett, J. M.), 43-78. Blackwell Scientific, Oxford.

181. Strogatz, S.H. (2001) Exploring complex networks. Nature, 410, 268-276.

182. Albert, R., Jeong, H. and Barabási, A.-L. (2000) Error and attack tolerance of complex networks. Nature, 406, 378-382.

183. Melián, C.J. and Bascompte, J. (2002) Complex networks: two ways to be robust? Ecology Letters, 5, 705-708.

184. Melián, C.J. and Bascompte, J. (2004) Food web cohesion. Ecology, 85, 352-358.

185. Williams, R.J., Berlow, E.L., Dunne, J.A., Barabasi, A.L. and Martinez, N.D. (2002) Two degrees of separation in complex food webs. Proceedings of the National Academy of Sciences of the United States of America, 99, 12913-12916.

186. Garlaschelli, D., Caldarelli, G. and Pietronero, L. (2003) Universal scaling relations in food webs. Nature, 423, 165-168.

186a. Garlaschelli, D., Caldarelli, G. and Pietronero, L. (2005) Food-web topology: Universal scaling in food-web structure? (reply). Nature, 435, E4.

187. Brose, U., Ostling, A., Harrison, K and Martinez, N.D. (2004) Unified spatial scaling of species and their trophic interactions. Nature, 428, 167-171.

188. Camacho, J. and Arenas, A. (2005) Universal scaling in food-web structure? Nature, 435, E3-E4.

189. Sugihara, G. (1983) Holes in niche space: a derived assembly rule and its relation to intervality. In Current Trends in Food Web Theory (DeAngelis, D. L., Post, W., and Sugihara, G.), 25-35. Report 5983, Oak Ridge National Laboratory, Oak Ridge, TN.

190. Williams, R.J. and Martinez, N.D. (2000) Simple rules yield complex food webs. Nature, 404, 180-183.

191. Cattin, M.F., Bersier, L.F., Banašek-Richter, C., Baltensperger, R. and Gabriel, J.P. (2004) Phylogenetic constraints and adaptation explain food-web structure. Nature, 427, 835-839.

192. Loeuille, N. and Loreau, M. (2005) Evolutionary emergence of size-structured food webs. Proceedings of the National Academy of Sciences of the United States of America, 102, 5761-5766.

193. Rossberg, A.G., Matsuda, H., Amemiya, T. and Itoh, K. (2005) An explanatory model for food-web structure and evolution. Ecological Complexity, 2, 312-321.

194. Sugihara, G. (1982) Niche hierarchy: structure assembly and organization in natural communities. Princeton University, Princeton, USA. 
195. Cohen, J.E. and Palka, Z.J. (1990) A stochastic theory of community food webs. $\mathrm{V}$. Intervality and triangulation in the trophic-niche overlap graph. American Naturalist, 135, 435-463.

196. Huxham, M., Beaney, S. and Raffaelli, D. (1996) Do parasites reduce the chances of triangulation in a real food web? Oikos, 76, 284-300.

197. Huxham, M., Raffaelli, D. and Pike, A. (1995) Parasites and food web patterns. Journal of Animal Ecology, 64, 168-176.

198. Cohen, J.E., Jonsson, T. and Carpenter, S.R. (2003) Ecological community description using the food web, species abundance, and body size. Proceedings of the National Academy of Sciences of the United States of America, 100, 17811786.

199. Reuman. D.C. and Cohen, J.E. (2004) Trophic links' length and slope in the Tuesday Lake food web with species' body mass and numerical abundance. Journal of Animal Ecology, 73, 852-866.

200. Cousins, S. H. (1985) The trophic continuum in marine ecosystems: Structure and equations for a predictive model. Canadian Journal of Fisheries and Aquatic Sciences, 213, 76-93.

201. Cody, M.L. (1974) Competition and the Structure of Bird Communities. Princeton University Press, Princeton.

202. Diamond, J.M. (1975) Assembly of species communities. In Ecology and Evolution of Communities (Cody, M. L. and Diamond, J. M.), 342-444. Belknap/Harvard University Press, Cambridge, MA.

203. Connor, E.F. and Simberloff, D. (1979) The assembly of species communities: Chance or competition. Ecology, 60, 1132-1140.

204. Schoener, T.W. (1983) Field experiments on interspecific competition. American Naturalist, 122, 240-285.

205. Connell, J.H. (1983) On the prevalence and relative importance of interspecific competition: Evidence from field experiments. American Naturalist, 122, 661-696.

206. Diamond, J.M. and Case, T.J. (1986) Community Ecology. Harper and Row Publ., New York.

207. Price, P.W. (1994) Phylogenetic constraints, adaptive syndromes, and emergent properties: from individuals to population dynamics. Researches on Population Ecology, 36, 3-14.

208. Price, P.W. (2003) Macroevolutionary theory on macroecological patterns. Cambridge University Press, Cambridge, UK.

209. Losos, J.B. (1996) Phylogenetic perspectives on community ecology. Ecology, 77, 1344-1354.

210. Robinson, W.D., Brawn, J.D. and Robinson, S.K. (2000) Forest bird community structure in central Panama: Influence of spatial scale and biogeography. Ecological Monographs, 70, 209-235.

211. Vanni, M.J., Flecker, A.S., Hood, J.M. and Headworth, J.L. (2002) Stoichiometry of nutrient recycling by vertebrates in a tropical stream: linking species identity and ecosystem processes. Ecology Letters, 5, 285-293. 
212. Vitt, L.J. and Pianka, E.R. (2005) Deep history impacts present-day ecology and biodiversity. Proceedings of the National Academy of Sciences of the United States of America, 102, 7877-7881.

213. Borrvall, C., Ebenman, B. and Jonsson, T. (2000) Biodiversity lessens the risk of cascading extinction in model food webs. Ecology Letters, 3, 131-136.

214. Solé, R.V. and Montoya, J.M. (2001) Complexity and fragility in ecological networks. Proceedings of the Royal Society of London Series B-Biological Sciences, 268, 2039-2045.

215. Dunne, J.A., Williams, R.J. and Martinez, N.D. (2002) Network structure and biodiversity loss in food webs: robustness increases with connectance. Ecology Letters, 5, 558-567.

216. Allesina, S. and Bodini, A. (2004) Who dominates whom in the ecosystem? Energy flow bottlenecks and cascading extinctions. Journal of Theoretical Biology, 230, 351-358.

217. Courchamp, F., Langlais, M. and Sugihara, G. (1999a) Cats protecting birds: modelling the mesopredator release effect. Journal of Animal Ecology, 68, 282292.

218. Courchamp, F., Langlais, M. and Sugihara, G. (1999b) Control of rabbits to protect island birds from cat predation. Biological Conservation, 89, 219-225.

219. Courchamp, F., Langlais, M. and Sugihara, G. (2000) Rabbits killing birds: modelling the hyperpredation process. Journal of Animal Ecology, 69, 154-164.

220. Strauss, S.Y. (1991) Direct, indirect, and cumulative effects of three native herbivores on a shared host plant. Ecology, 72, 543-558

221. Strauss, S.Y. and Irwin, R.E. (2004) Ecological and evolutionary consequences of multispecies plant-animal interactions. Annual Review of Ecology Evolution and Systematics, 35, 435-466.

222. Ulanowicz, R.E. and Puccia, C.J. (1990) Mixed trophic impacts in ecosystems. Coenoses, 5, 7-16.

223. Hairston, N.G., Smith, F.E. and Slobodkin, L.B. (1960) Community structure, population control and competition. American Naturalist, 94, 421-425.

224. Fretwell, S.D. (1977) The regulation of plant communities by the food chains exploiting them. Perspectives in Biology and Medicine, 20, 169-185.

225. Carpenter, S.R., Kitchell, J.F., Hodgson, J.R., Cochran, P.A., Elser, J.J., Elser, M.M., Lodge, D.M., Kretchmer, D., He, X. and von Ende, C.N. (1987) Regulation of lake primary productivity by food web structure. Ecology, 68, 1863-1876.

226. Carpenter, S.R. and Kitchell, J.F. (1988) Consumer control of lake productivity. BioScience, 38, 764-769.

227. Strong, D.R. (1992) Are trophic cascades all wet? Differentiation and donorcontrol in speciose ecosystems. Ecology, 73, 747-754.

228. Pace, M.L., Cole, J.J., Carpenter, S.R. and Kitchell, J.F. (1999) Trophic cascades revealed in diverse ecosystems. Trends in Ecology and Evolution, 14, 483-488.

229. Chase, J.M. (2000) Are there real differences among aquatic and terrestrial food webs? Trends in Ecology and Evolution, 15, 408-412. 
230. Schmitz, O.J., Hamback, P.A. and Beckerman, A.P. (2000) Trophic cascades in terrestrial systems: A review of the effects of carnivore removals on plants. American Naturalist, 155, 141-153.

231. Schmitz, O.J. (1994) Resource edibility and trophic exploitation in an old-field food web. Proceedings of the National Academy of Sciences of the United States of, 91, 5364-5367.

232. Schmitz, O.J., Beckerman, A.P. and O'Brien, K.M. (1997) Behaviorally mediated trophic cascades: Effects of predation risk on food web interactions. Ecology (Washington D C), 78, 1388-1399.

233. MacKay, N.A. and Elser, J.J. (1998) Factors potentially preventing trophic cascades: Food quality, invertebrate predation, and their interaction. Limnology and Oceanography, 43, 339-347.

234. Bell, T. (2002) The ecological consequences of unpalatable prey: phytoplankton response to nutrient and predator additions. Oikos, 99, 59-68.

235. Morin, P.J. and Lawler, S.P. (1995) Food web architecture and population dynamics: Theory and empirical evidence. Annual Review of Ecology and Systematics, 26, 505-529.

236. McCann, K.S., Hastings, A. and Strong, D.R. (1998) Trophic cascades and trophic trickles in pelagic food webs. Proceedings of the Royal Society of London Series B-Biological Sciences, 265, 205-209.

237. Holt, R.D. (1977) Predation, apparent competition, and the structure of prey communities . Theoretical Population Biology, 12, 197-229.

238. Holt, R.D. and Lawton, J.H. (1994) The ecological consequences of shared natural enemies. Annual Review of Ecology and Systematics, 25, 495-520.

239. Putman, R.J. (1994) Community Ecology. Chapman and Hall, London.

240. Milo, R., Shen-Orr, S., Itzkovitz, S., Kashtan, N., Chklovskii, D. and Alon, U. (2002) Network motifs: simple building blocks of complex networks. Science, 298, 824-827.

241. Polis, G.A., Myers, C.A. and Holt, R. (1989) The ecology and evolution of intraguild predation: potential competitors that eat each other. Annual Review of Ecology and Systematics, 20, 297-330.

242. Holt, R.D. (1996) Community modules. In Multitrophic Interactions in Terrestrial Communities (Gange, A. C. and Brown, V. K.). 333-350. Blackwell Science, Oxford, UK.

243. Bascompte, J., Melián, C.J. and Sala, E. (2005) Interaction strength combinations and the overfishing of a marine food web. Proceedings of the National Academy of Sciences of the United States of America, 102, 5443-5447.

244. Memmott, J., Godfray, H.C.J. and Gauld, I.D. (1994) The structure of a tropical host-parasitoid community. Journal of Animal Ecology, 63, 521-540.

245. Memmott, J. and Godfray, H.C.J. (1994) The use and construction of parasitoid webs. In Parasitoid community ecology (Hawkins, B. A. and Sheehan, W.). 300318. Oxford University Press, Oxford.

246. Wilson, H.B., Hassell, M.P. and Godfray, H.C.J. (1996) Host-parasitoid food webs: Dynamics, persistence, and invasion. American Naturalist, 148, 787-806. 
247. Müller, C.B., Adriaanse, I.C.T., Belshaw, R. and Godfray, H.C.J. (1999) The structure of an aphid-parasitoid community. Journal of Animal Ecology, 68, 346370.

248. Rott, A.S. and Godfray, H.C.J. (2000) The structure of a leafminer-parasitoid community. Journal of Animal Ecology, 69, 274-289.

249. Valladares, G.R., Salvo, A. and Godfray, H.C.J. (2001) Quantitative food webs of dipteran leafminers and their parasitoids in Argentina. Ecological Research, 16, 925-939.

250. Lewis, O.T., Memmott, J., Lasalle, J., Lyal, C.H.C., Whitefoord, C. and Godfray, H.C.J. (2002) Structure of a diverse tropical forest insect-parasitoid community. Journal of Animal Ecology, 71, 855-873.

251. Müller, C.B. and Godfray, H.C.J. (1997) Apparent competition between two aphid species. Journal of Animal Ecology.66.1997.57-64., 57-64.

252. Morris, R.J., Lewis, O.T. and Godfray, H.C.J. (2004) Experimental evidence of apparent competition in a tropical forest food web. Nature, 428, 310-313.

253. Inger, R.F. and Colwell, R.K. (1977) Organization of contiguous communities of amphibians and reptiles in Thailand. Ecological Monographs 47, 229-253.

254. Hofer, U., Bersier, L.F. and Borcard, D. (2004) Relating niche and spatial overlap at the community level. Oikos, 106, 366-376.

255. Jordano, P. (1987) Patterns of mutualistic interactions in pollination and seed dispersal: Connectance, dependence asymmetries, and coevolution. American Naturalist, 129, 657-677.

256. Jordano, P. (1995) Angiosperm fleshy fruits and seed dispersers: A comparativeanalysis of adaptation and constraints in plant-animal interactions. American Naturalist, 145, 163-191.

257. Memmot, J. (1999) The structure of a plant-pollinator food web. Ecology Letters, 2, 276-280.

258. Kearns, C.A., Inouye, D.W. and Waser, N.M. (1998) Endangered mutualisms: The conservation of plant-pollinator interactions. Annual Review of Ecology and Systematics, 29, 83-112.

259. Bascompte, J., Jordano, P., Melián, C.J. and Olesen, J.M. (2003) The nested assembly of plant-animal mutualistic networks. Proceedings of the National Academy of Sciences of the United States of America, 100, 9383-9387.

260. Jordano, P., Bascompte, J. and Olesen, J.M. (2003) Invariant properties in coevolutionary networks of plant-animal interactions. Ecology Letters, 6, 69-81.

261. Tiunov, A.V. and Scheu, S. (2005) Facilitative interactions rather than resource partitioning drive diversity-functioning relationships in laboratory fungal communities. Ecology Letters, 8, 618-625.

262. Jones, C.G., Lawton, J.H. and Shachak, M. (1997) Positive and negative effects of organisms as physical ecosystem engineers. Ecology, 78, 1946-1957.

263. Wilby, A., Shachak, M. and Boeken, B. (2001) Integration of ecosystem engineering and trophic effects of herbivores. Oikos, 92, 436-444.

264. Berkenbusch, K. and Rowden, A.A. (2003) Ecosystem engineering - moving away from 'just-so' stories. New Zealand Journal of Ecology, 27, 67-73. 
265. Elser, J.J., Sterner, R.W., Gorokhova, E., Fagan, W.F., Markow, T.A., Cotner, J.B., Harrison, J.F., Hobbie, S.E., Odell, G.M. and Weider, L.J. (2000) Biological stoichiometry from genes to ecosystems. Ecology Letters, 3, 540-550.

266. Banašek-Richter, C., Cattin, M.F. and Bersier, L.F. (2004) Sampling effects and the robustness of quantitative and qualitative food-web descriptors. Journal of Theoretical Biology, 226, 23-32.

267. Sheppard, S.K. and Harwood, J.D. (2005) Advances in molecular ecology: tracking trophic links through predator-prey food-webs. Functional Ecology, 19, 751-762.

268. Holt, R.D. (2002) Food webs in space: On the interplay of dynamic instability and spatial processes. Ecological Research, 17, 261-273.

269. McCann, K.S., Rasmussen, J.B. and Umbanhowar, J. (2005) The dynamics of spatially coupled food webs. Ecology Letters, 8, 513-523.

270. Tscharntke, T., Klein, A.M., Kruess, A., Steffan-Dewenter I. and Thies C. (2005) Landscape perspectives on agricultural intensification and biodiversity ecosystem service management. Ecology Letters, 8, 857-874.

271. Leibold, M.A., Holyoak, M., Mouquet, N., Amarasekare, P., Chase, J.M., Hoopes, M.F., Holt, R.D., Shurin, J.B., Law, R., Tilman, D., Loreau, M. and Gonzalez, A. (2004) The metacommunity concept: a framework for multi-scale community ecology. Ecology Letters, 7, 601-613. 